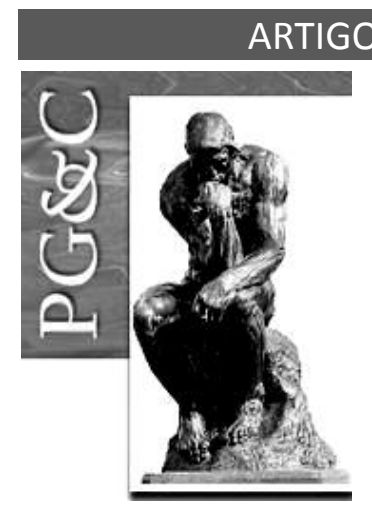

\title{
A EVOLUÇÃO DAS MUDANÇAS TÉCNICAS, TECNOLÓGICAS E DA INOVAÇÃO E SEUS IMPACTOS NA PRODUÇÃO DO CONHECIMENTO ORGANIZACIONAL: APRENDIZAGEM ORGANIZACIONAL E OPEN USER INNOVATION
}

\author{
Cassia Aparecida Corsatto \\ Doutoranda em Ciência, Tecnologia e Sociedade pela Universidade \\ Federal de São Carlos, Brasil. \\ E-mail: cassiacorsatto@gmail.com \\ Wanda Aparecida Machado Hoffmann \\ Doutora em Ciência e Engenharia dos Materiais pela Universidade \\ Federal de São Carlos, Brasil. Professora da Universidade \\ Federal de São Carlos, Brasil. \\ E-mail: wanda@nit.ufscar.br
}

\begin{abstract}
Resumo
Este artigo apresenta um ensaio teórico sobre os impactos da produção do conhecimento organizacional na geração da inovação, observando a evolução da inovação ao longo da história desde os estudos das mudanças técnicas, tecnológicas e seus impactos para a evolução da inovação, no contexto da aprendizagem organizacional, learning organization e das práticas organizacionais da open user innovations. A título de contextualização, apresenta os conceitos de tecnologia e inovação e as formas de produção do conhecimento da mesma natureza para cada um destes temas. Apresenta-se ainda o contexto da produção do conhecimento organizacional, sua importância para o processo de geração da inovação, suas conexões com a aprendizagem organizacional a partir do indivíduo ou de um conjunto de indivíduos e da aprendizagem a partir da experiência do usuário. Foi desenvolvido utilizando a literatura como guia, considerando questões afetas à evolução tecnológica, inovação e conhecimento organizacional, buscando contextualizar os impactos da evolução tecnológica na geração da inovação e produção do conhecimento organizacional.
\end{abstract}

Palavras-chave: Aprendizagem Organizacional. Inovação. Mudança Técnica. Conhecimento. Tecnologia.

\section{THE EVOLUTION OF THE TECHNICAL, TECHONOLIGICAL AND THE INNOVATION CHANGES AND ITS IMPACTS ON ORGANIZATIONAL KNOWLEDGE PRODUCTION: LEARNING ORGANIZATION AND OPEN USER INNOVATION}

\begin{abstract}
This paper presents a theoretical addressing about the impacts of the organizational knowledge's production and the context of the innovations process, observing the historical evolution of innovation since the study of technical, technological changes and the historical evolution of innovation and organizational learning in the context of the learning organization and organizational practices of open user innovations. Discusses technological and innovations concepts and talk about the historical importance of technical and technological changes and new forms of organizational knowledge production for the generation of innovations. It was develop using literature searches as a guide, considering questions related to advances in technology, innovation and organizational knowledge, seeking to contextualize the impact of technological developments in the generation of innovation and production of organizational knowledge.
\end{abstract}

Keywords: Organizational Learning. Innovation. Technical Changes. Knowledge. Technology.

Perspectivas em Gestão \& Conhecimento, João Pessoa, v. 6, n. 2, p. 4-31, jul./dez. 2016. http://periodicos.ufpb.br/ojs2/index.php/pgc. ISSN: 2236-417X. Publicação sob Licença (cc) EY-NC-ND 


\section{INTRODUÇÃO}

A evolução histórica das mudanças técnicas, tecnológicas e das inovações levou o mundo a grandes transformações ao longo dos séculos, deixando marcas e causando impactos profundos no desenvolvimento científico e tecnológico e, consequentemente nas discussões sobre a produção de conhecimentos da mesma natureza. Esta dinâmica secular causou e ainda causa mudanças na configuração econômica do mundo de forma que os impactos e os paradigmas relacionados à evolução das mudanças técnicas e tecnológica são objetos de estudos e pesquisas que contribuíram para o surgimento das discussões sobre o desenvolvimento da inovação e a produção do conhecimento organizacional que as origina.

A relação entre tecnologia, inovação e produção do conhecimento, bem como suas dimensões no contexto organizacional vêm evoluindo ao longo do tempo, desta forma, vale-se da história para resgatar questões que nesta perspectiva permanecem contemporâneas, impactando na estrutura de gestão das empresas modernas. Entende-se que a compreensão desse processo por parte das empresas/organizações contribuirá para a busca de modelos, métodos ou práticas inovadoras que levem em conta a importância da produção do conhecimento para a geração de inovação.

Tendo em vista a abordagem proposta, este artigo é composto por quatro partes além da introdução, a primeira apresenta a contribuição histórica e econômica dos estudos da inovação e sua evolução a partir das mudanças técnicas e dos avanços tecnológicos, apresentadas de acordo com a ocorrência das evoluções em períodos de tempo na história, quais sejam: i) dos estudos das mudanças técnicas, tecnológicas e das inovações ocorridas no período de 1750-1914; ii) a tecnologia na economia malthusiana, ocorrida no período pré-1800 se estendendo até aproximadamente 1830; iii) a tecnologia na primeira revolução industrial, uma nova abordagem; iv) a transição para o crescimento moderno cujas ocorrências se deram entre 1830-1880 - a evolução da inovação e; v) o período que sucede esses eventos e que vai até 1914. Ressalta-se que esta etapa do ensaio foi desenvolvida tendo como referencial teórico prioritário o capítulo 2 "The Contribuition of Economic History to the Study of Innovation and Technical Change: 1750 - 1914 do Handbook of the Economics of Innovation. A segunda parte apresenta os conceitos de tecnologia e inovação e sua interação com a produção do conhecimento da mesma natureza. Na terceira parte serão apresentados os temas relacionados à produção do conhecimento organizacional, sua importância no processo de inovação e suas conexões com as formas de aprendizagem organizacional, sob o ponto de vista das learning organization e da open user innovation, esta perspectiva de produção do conhecimento é ampliada para a observação da utilização de práticas de aprendizagem na organização que aprende (learning organizations), sua importância para a geração de inovação e para a utilização da open user innovation e, em seguida apresenta-se algumas considerações relevantes sobre o tema. Este artigo foi desenvolvido utilizando a literatura como guia, considerando questões afetas à evolução tecnológica, inovação e conhecimento organizacional, buscando contextualizar os impactos das mudanças técnicas e tecnológicas e sua evolução para as inovações de todas as naturezas e a importância da aprendizagem organizacional na produção do conhecimento para a geração destas inovações.

\section{CONTRIBUIÇÃO HISTÓRICA E ECONÔMICA DOS ESTUDOS DA INOVAÇÃO E SUA EVOLUÇÃO A PARTIR DAS MUDANÇAS TÉCNICAS E AVANÇOS TECNOLÓGICOS}

As discussões sobre tecnologia e inovação são extensas e seus impactos nas dimensões do desenvolvimento técnico, tecnológico, da inovação e na produção do conhecimento organizacional são significativos, particularmente no que se refere à evolução das tecnologias (CORSATTO, 2016). Desta forma, observando o contexto histórico, econômico e social da

Perspectivas em Gestão \& Conhecimento, João Pessoa, v. 6, n. 2, p. 4-31, jul./dez. 2016 
evolução tecnológica e inovativa, Mokyr (2010, p. 15) alerta para o fato de que "[...] technology does not 'drive' history", ou seja, a história não foi feita somente de fatos e eventos tecnológicos apesar dos seus comprovados efeitos no desenvolvimento da humanidade.

Seguindo esta abordagem, a apresentação das contribuições da história para os estudos da inovação, da tecnologia, das mudanças técnicas e da produção do conhecimento organizacional se dará por meio da apresentação de dois períodos históricos importantes nesta construção discutidos por Mokyr no Handbook of the Economics of Innovation, quais sejam: i) dos estudos das mudanças técnicas, tecnológicas e das inovações ocorridas no período de 1750-1914 e; ii) dos estudos das mudanças tecnológicas e da inovação e a dinâmica da evolução industrial ocorrida a partir do século XX.

\subsection{Dos Estudos das Mudanças Técnicas, Tecnológicas e das Inovações ocorridas no período de 1750-1914}

Com o propósito de elucidar o desenvolvimento da ciência e da tecnologia na economia moderna, o Handbook of the Economics of Innovations traz um capítulo com as contribuições históricas dos estudos da inovação, das mudanças técnicas e tecnológicas ocorridas no período de 1750-1914 enfatizando sua importância para o mundo contemporâneo. Há que se considerar que no final do século XVII e até meados do século XVIII, embora tenham ocorrido inventos significativos que foram precursores de grandes mudanças tecnológicas e suas subsequentes inovações, há poucos registros dos métodos e formas nos quais os mesmos foram desenvolvidos e dos seus impactos no crescimento econômico, os registros históricos existentes apontam para mudanças de cunho técnico e cujo conhecimento utilizado na maioria das vezes era o tácito (FIGUEIREDO, 2015; HALL; ROSENBERG, 2010).

Pode-se dizer que o marco histórico das grandes invenções e inovações se deu entre meados do século XVIII e no século XIX com o advento da Revolução Industrial, quando preocupações com o desenvolvimento econômico começavam a se fazer presentes nas teorias das ciências econômicas e as questões da ciência e da tecnologia começaram se tornar evidentes no contexto sócio econômico mundial, enfatizando as discussões sobre a inovação e seus processos no contexto das organizações.

Em se tratando de inovação, tecnologia e economia, seu crescimento e sua dinâmica, Mokyr (2010, p. 13) em sua visão histórica afirma que as referências sobre o assunto são poucas eram totalmente inexpressivas. Mokyr (2010) apresenta as poucas referências encontradas sob três pontos de vista diferentes relatados por estudiosos da época, particularmente aqueles cujos interesses estavam focados nas questões econômicas que, a partir de observações empíricas, perceberam que o crescimento antes de 1800 foi praticamente nulo ou muito lento e que o pouco crescimento que ocorreu foi manifestado nas economias que faziam parte do "clube de convergência", que surgiu depois de 1830 . O segundo ponto de vista, um pouco mais antigo, porém "não menos venerável" segundo Mokyr (2010, p. 13), é o de que a economia da modernidade estava baseada na expansão de bens, no fator mercado e na crescente interdependência das famílias e das empresas e; a terceira visão

\footnotetext{
1 São denominados "clubes de convergência os países, territórios ou regiões que apresentam semelhanças econômicas entre si. Existem várias formas de convergência econômica, segundo Galor (1996), na hipótese de convergência condicional, por exemplo, "a renda per capita dos países ou regiões que são idênticos em relação a suas características estruturais (preferências, tecnologias, capital humano, políticas governamentais, entre outras) convergem no longo prazo, se suas condições iniciais de desenvolvimento estão muito próximas. Desta forma, os "clubes de convergência" são caracterizados pela semelhança de suas condições de desenvolvimento estrutural, tecnológica, de políticas públicas, de capital social e humano, no tempo.
}

Perspectivas em Gestão \& Conhecimento, João Pessoa, v. 6, n. 2, p. 4-31, jul./dez. 2016 
focava a organização industrial, colocando a firma no centro da economia, considerando a concentração crescente de trabalhadores e considerando sua sujeição às regras, disciplina e coordenação top-down ${ }^{2}$ como a essência de modelo de negócio da economia moderna.

No entanto, nenhuma dessas formas de interpretação, conforme o autor, seria convincente sem a fundamental mudança que sobrepõe todas as outras, que foi denominada de mudança tecnológica, que caracterizou a Revolução Industrial e trouxe o crescimento da economia moderna, observe-se que naquele momento o foco era no surgimento de aparatos com nuances tecnológicas e no seu processo de evolução ou melhoria, as então denominadas, inclusive por Schumpeter (1985) de inovações tecnológicas. Sob este aspecto, Mokyr (2010) propõe uma reflexão sobre, como se deu o avanço tecnológico. A teoria moderna do crescimento endógeno, segundo ele, postula que a inovação é produzida em um sistema de economia de incentivos cujas entradas e saídas estão vinculadas ao capital físico, capital humano, economia de escala, como se destaca:

Modern endogenous growth theory has postulated that innovation is "produced" within the system, subject to economic incentives and should be regarded as an output of a production of inputs, where physical capital, human capital, R\&D, and economies of scale all play major rules. (MOKYR, 2010, p. 13)

Com esta visão, o autor traz à tona discussões sobre o desenvolvimento tecnológico e da inovação como um processo evolutivo e cumulativo, onde estão envolvidos diretamente: estrutura, pessoas, capital, mercado e, consequentemente, a produção do conhecimento e desenvolvimento tecnológico, que evoluíram a partir de duas teorias: a internalista e a externalista (MOKYR, 2010, p. 14). A primeira observa uma lógica autônoma, um processo evolucionista no qual um avanço conduz a outro, onde contingências representam a regra maior e onde o passado determina o futuro, já a teoria externalista pensa as mudanças tecnológicas como um fator determinado pelas necessidades econômicas e essas necessidades estimulam invenções que induzem às inovações, guiadas pelos fatores preço e pelos recursos para investimentos (KUHN, 2011; MANSFIELD, 1968; TEECE, 2010).

Dando sequência à proposta deste artigo e corroborando com os três pontos de vista apresentados por Mokyr (2010) abordando os impactos da tecnologia no crescimento da economia, apresentam-se os principais fatores, perspectivas e visões dos efeitos tecnológicos na economia em diferentes períodos da história, quais sejam: i) a tecnologia na economia Malthusiana, que ocorreu no período pré-1800 se estendendo até aproximadamente 1830; ii) a tecnologia na Primeira Revolução Industrial; uma nova abordagem; iii) a transição para o crescimento moderno cujas ocorrências se deram entre 1830-1880 e; iv) o período após esses eventos, que vai até 1914.

2.1.1 A tecnologia na economia Malthusiana, ocorrida no período pré-1800 até aproximadamente 1830

A tecnologia na economia Malthusiana teve suas origens registradas na sociedade pré1800, onde na Europa e em outros países do mundo começaram "a surgir equipamentos e invenções que se tornaram úteis para o desenvolvimento da sociedade." (MOKYR, 2010, p. 16). No entanto, observou-se que tais invenções foram desenvolvidas em sua grande maioria a

\footnotetext{
${ }^{2}$ N.A - Conforme o significado da palavra, top down (de cima para baixo) se refere a um modelo de gestão baseado em níveis hierárquico de cima para baixo. Conforme Nonaka e Takeuchi (1997, p. 142) "uma organização top down é moldada como uma pirâmide, se visualizarmos as relações duais de altos gerentes versus gerentes médios e gerentes médios versus funcionários de linha de frente".
}

Perspectivas em Gestão \& Conhecimento, João Pessoa, v. 6, n. 2, p. 4-31, jul./dez. 2016 
partir dos conhecimentos tácitos e das habilidades técnicas de seus inventores (geralmente artesãos), sem a compreensão do porquê ou como funcionavam (DRUCKER, 1993, MOKYR, 2010). Tal desconhecimento não foi fator impeditivo para que essas sociedades "produzissem aço sem compreensão dos processos metalúrgicos, produzissem cerveja sem compreender a importância das leveduras, criassem animais sem técnicas de genética, praticassem a rotação de culturas e cultivassem sem aplicar fertilizante" (MOKYR, 2010, p. 16), ou fabricassem utensílios de ferro sem conhecer as características químicas do metal (FIGUEIREDO, 2015) só para citar alguns exemplos de práticas de utilização do conhecimento tácito predominante à época.

A tecnologia, conforme Mokyr (2010), pode mudar mesmo quando o suporte subjacente do conhecimento proposicional (a base epistêmica) não se amplia, desta forma, embora esse desconhecimento não fosse fator impeditivo para "o avanço do desenvolvimento de novos equipamentos, a falta de compreensão dos processos naturais se caracterizou como motivo para o baixo ou quase inexistente crescimento da economia" (MOKYR, 2010, p. 16), não tendo sido, no entanto, caracterizado como a única razão pela qual isso se deu. $\mathrm{O}$ autor argumenta que diversos outros fatores influenciaram o baixo crescimento, entre eles a sede de poder, as taxas de impostos, as associações/cooperativas, os monopólios, a igreja e outros, conforme segue:

\begin{abstract}
Many problems remain with this interpretation (Mokyr and Voth, 2010), and it needs to be complemented by an alternative negative feedback mechanism, namely the fact that economic growth often was undone by the greed of poorer but more violent predatory neighbors and that of tax collectors, guild members, priests, monopolists, and other seekers of exclusionary rents. (MOKYR, 2010, p. 16).
\end{abstract}

Apesar dessas variáveis que afetaram a expansão comercial e os avanços tecnológicos no século XVII há um consenso de que antes da Revolução Industrial alguns ganhos e algum resultado econômico podem ser atribuídos ao comércio e ao mercado e, como menciona Mokyr (2010, p. 17) "[...] technology, then, was not stagnante", tendo evoluído e apresentado algum avanço cumulativo na agricultura, têxteis, construção naval, comunicações, metalurgia e uso de energia. Assim, na economia Malthusiana, conforme registra a história, a maioria dos inventos foram desenvolvidos por artesãos, que geralmente se organizavam em associações que desempenhavam um papel importante no seu treinamento. Eles eram bem treinados nas suas habilidades, além disso, suas capacidades e mentes criativas tornaram possível a aplicação de técnicas acuradas na criação de equipamentos, e, embora fossem hábeis em suas especialidades, seu nível de conhecimento era diferente do conhecimento necessário para fazer descobertas ou inovações científicas (DRUCKER, 1993, MOKYR, 2010). Para caracterizar esta diferença Mokyr (2010, p. 17) utiliza o termo "competência" que diferencia a categorização e as características da aplicação do conhecimento.

Os artesãos eram dotados de habilidades técnicas, os cientistas são dotados de conhecimento, competência e compreensão epistêmica dos processos de criação, ou seja, os artesãos "[...] normally reproduced existing technology and in that process incremental microinventive sequences could lead to some improvements, but eventually will fizzle out" (MOKYR, 2010, p. 18), sendo, desta forma, reconhecidamente bons em fazer melhorias incrementais nos processos existentes e hábeis em imitações, porém, como seus conhecimentos de processos eram limitados, a falta de registro dos mesmos os impedia de replicar máquinas e equipamentos com a mesma precisão, necessitando de auxílio. Surge neste período uma nova abordagem denominada de Primeira Revolução Industrial e considerando a atuação dos artesãos surge também um questionamento importante: "Seriam

Perspectivas em Gestão \& Conhecimento, João Pessoa, v. 6, n. 2, p. 4-31, jul./dez. 2016 
as habilidades dos artesãos, por si só, capazes de gerar algo como a Revolução Industrial?" (MOKYR, 2010, p. 18). Afinal, durante o regime Malthusiano, a economia foi dominada por eles, contando com a sua capacidade de inovação, ainda que limitada e com a pouca difusão de conhecimento útil, formal e sistemático.

Esta nova abordagem apontava para uma sociedade que estava pronta para definir um padrão de comportamento social e econômico diferenciado, que despertava para visões e percepções voltadas para a importância da sistematização e padronização de máquinas, equipamentos e processos, buscando com isto, formas de documentar e disponibilizar o conhecimento produzido até então em beneficio desta nova sociedade. Observa-se desta forma que a transição da economia da era Malthusiana para Primeira Revolução Industrial que ocorreu durante o século XVIII,

\begin{abstract}
não se tratava prioritariamente da passagem de uma economia orgânica para uma economia mineral, mas sim da passagem de um paradigma tecnológico cujo conhecimento utilizado era empírico, não sistematizado, na maioria das vezes pouco mais do que um conjunto de entendimentos tácitos de como a natureza trabalhou e como materiais se comportavam e reagiam ao calor e aos movimentos, para um paradigma tecnológico em que este tipo de conhecimento passou a ser recolhido de forma sistemática e organizada e analisado (MOKYR, 2010, p. 18),
\end{abstract}

tornando-se cada vez mais o agente dinâmico que mudou a economia.

\title{
2.1.2 A tecnologia na Primeira Revolução Industrial: uma nova abordagem
}

A aceleração da economia que segue neste período e que dá origem à Primeira Revolução Industrial, e à nova abordagem onde se constata que "[...] The real miracle is not that these Malthusian societies grew so slowly, but that they were, in the end, replaced by a society in which rapid growth became the norm." (MOKYR, 2010, p. 18). A Primeira Revolução Industrial dá início a um novo padrão de comportamento social e econômico, uma nova ordem, onde o crescimento acelerado tornou-se norma (MOKYR, 2010, p. 19). Essa nova ordem ocorreu no período marcado pela era da razão, denominada lluminismo ${ }^{3}$, também chamada por Mokyr (2010) de "Iluminismo Industrial", tendo sido considerada uma tentativa de reconhecer os problemas de ordem social, econômica, tecnológica entre outros existentes e corrigi-los, uma tentativa de trazer de volta o sonho alimentado por Bacon ${ }^{4}$ (1561-1626) de tornar útil o conhecimento. Bacon (1561-1626), menciona Mokyr (2010, p. 19), acreditava que a ciência pudesse servir para a criação de conhecimentos a serem utilizados para o progresso e bem-estar social, dando origem ao pensamento racional e ao desenvolvimento do empirismo e de alguma forma ao processo de registros e documentação de conhecimentos de natureza científica e tecnológica que avançou para a produção do conhecimento organizacional e sua utilização no desenvolvimento das inovações (CORSATTO; HOFFMANN, 2015).

\footnotetext{
${ }^{3}$ O lluminismo foi um movimento intelectual que surgiu durante o século XVIII na Europa, que defendia o uso da razão (luz) contra o antigo regime (trevas) e pregava maior liberdade econômica e política. Disponível em: http://www.sohistoria.com.br/resumos/iluminismo.php. Acesso em: 20 fev. 2015.

${ }^{4}$ N.A. - Francis Bacon (1561-1626), político, filósofo, ensaísta, inglês, também é considerado fundador da ciência moderna, que, embora seja anterior ao período estudado, seu pensamento teve forte influência, pelos estudos da metodologia científica, pelo desenvolvimento do empirismo e do pensamento racionalista. Disponível em: http:// desenvolvendo o pensamento critico .blogspot. com.br 2010/06/francis-bacon-e-o-empirismo.html. Acesso em: 07 jul. 2015.
}

Perspectivas em Gestão \& Conhecimento, João Pessoa, v. 6, n. 2, p. 4-31, jul./dez. 2016 
O pensamento baconiano segundo Mokyr (2010) teve forte influência nas gerações subsequentes, que seguindo suas abordagens e visão, criaram a Royal Society com a proposta de "estimular a utilização do conhecimento para estabelecer uma ponte entre a ciência formal e a prática atual" (MOKYR, 2010 p. 19), dando início ao processo de compreensão das formas de produção do conhecimento de todas as naturezas, sua organização e sistematização. A constituição da Royal Society começou a despertar na sociedade a consciência de que "a prosperidade de uma nação dependia em grande medida do conhecimento e das práticas de melhoramento de artes úteis." (MOKYR, 2010, p. 20). Esta condição provocou uma transformação na educação e acelerou a criação do conhecimento, uma vez que, na segunda metade do século XVIII começou a surgir um grande número de academias e sociedades formais dedicadas a combinar filosofia natural com artes úteis, reunindo empresários e industriais com cientistas e filósofos, modificando a matriz social e econômica vigentes (DRUCKER, 1993; MOKYR, 2010; SNOW, 1963).

Ainda na proposta de tornar útil o conhecimento produzido, no final do século XVIII, "duas figuras paradigmáticas do lluminismo Industrial, Sir Joseph Banks e Benjamin Thompson fundaram a Royal Institution, dedicada à pesquisa, desenvolvimento e fornecimento de conteúdos sobre questões científicas e tecnológicas" (MOKYR, 2010, p. 20).

Ao descrever em detalhe os processos, experiências e práticas tecnológicas levava-se em conta uma gama enorme de informações coletadas a partir das experiências e com isto "cientistas e ciência (não são a mesma coisa) tiveram alguns êxitos espetaculares no desenvolvimento de novas técnicas de produção." (MOKYR, 2010, p. 21). E ainda, conforme Mokyr (2010, p. 21) historiadores relatam "avanços metodológicos da engenharia experimental ao perceber que as melhorias em sistemas tecnológicos podiam ser testadas apenas pelas variações de componentes um de cada vez." Com isto, muitos instrumentos e ferramentas desenvolvidos durante o lluminismo "desempenharam papéis importantes, podendo ser reconhecidas como melhorias tecnológicas" (MOKYR, 2010, p. 21), no entanto, a maioria das inovações pioneiras associadas à Revolução Industrial não dependeram muito desse conhecimento, visto que grande parte delas foi obtida à base de experimentações movidas por conhecimentos adquiridos pela experiência (FIGUEIREDO, 2015, MOKYR).

Apesar disso, de acordo com Mokyr (2010), esse conhecimento contribuiu para a ampliação da base epistêmica de algumas técnicas que estavam em uso durante séculos, explicando em parte o porquê e como as coisas foram desenvolvidas e, explicando as novas tecnologias que surgiram no período. Essas novas tecnologias deram origem às fábricas, que são consideradas um conjunto de coisas, entre elas "local onde as técnicas foram testadas e executadas" (MOKYR, p. 21) dando origem ao crescente processo de especialização.

Assim, tem-se que, durante a primeira Revolução Industrial o progresso tecnológico se espalhou por muitos setores da indústria, dando início ao princípio do desenvolvimento econômico e social, uma vez que seu avanço não se deu apenas em "uma indústria ou outra, mas foi um impulso para o progresso de forma ampla" (MOKYR, 2010, p. 22), podendo-se concluir que a importância histórica da primeira Revolução Industrial para o crescimento econômico moderno não se deu "tanto nas indústrias de transformações, mas na capacidade das economias ocidentais de sustentar o progresso tecnológico" (MOKYR, 2010, p. 22), oportunizando a transição e evolução para a segunda Revolução Industrial.

\subsubsection{A transição para o crescimento moderno cujas ocorrências se deram entre 1830-1880}

Considerou-se a fase de transição para o crescimento moderno como a terceira perspectiva dos efeitos tecnológicos no processo da produção do conhecimento e da inovação, tendo esta ocorrido no período de 1830-1880. Neste período, ainda sob o impacto do iluminismo e sob regimes conservadores instituídos em toda a Europa, as preocupações com

Perspectivas em Gestão \& Conhecimento, João Pessoa, v. 6, n. 2, p. 4-31, jul./dez. 2016 
as teorias do desenvolvimento econômico já se faziam presentes, como manifestava Adam Smith (1723-1790) em seu livro "A Riqueza das nações - Investigação sobre sua natureza e suas causas", conforme Viotti et al. (1997, p. 9), sendo caracterizado como o período de transição para o crescimento moderno que ocorreu entre 1830-1880 dando origem à segunda Revolução Industrial.

Nesse contexto, as economias no ocidente em 1830 se posicionavam mais ou menos comprometidas com o desenvolvimento econômico dada a complexidade da situação, uma vez que a influência da economia política existente se tornou muito poderosa para ignorar os regimes reacionários. Cientes do impacto do desenvolvimento econômico "os poderes políticos e militares apoiaram a criação e difusão dos conhecimentos úteis nas suas mais diversas formas." (MOKYR, 2010, p. 23)

Assim, aquele foi considerado um período profícuo para o desenvolvimento das nações, "o mais espetacular da história da economia para o desenvolvimento de máquinas e equipamentos e teecnologias de transportes que mudaram a história do mundo." (MOKYR, 2010, p. 23). Considerando as tecnologias de transporte citadas por Mokyr (2010), traz-se o exemplo da ferrovia cujo desenvolvimento foi conduzido por engenheiros britânicos, além da evolução da engenharia mecânica, entre outros exemplos como o desenvolvimento de máquinas e equipamentos que, de acordo com Mokyr (2010, p. 24), embora fossem "bem servidos pelas altas habilidades e amplo conhecimento prático dos engenheiros mecânicos, em uma época em que a destreza e experiência ainda podiam ser substituídas por um treinamento formal em matemática e física", no entanto, eles ainda eram na sua grande maioria construídos por pessoas com pouca ou nenhuma educação formal,

It was mostly designed and built by people with little or no formal education, but who had mastered a profound if informal understanding of what did and did not work through a combination of natural talent and access to the right masters. (MOKYR, 2010, p. 24).

Em que pesem estas questões, foi um período considerado de grande impulso para a racionalização da manufatura, muitas máquinas e equipamentos se tornaram padronizados, mudanças nas formas e na divisão do trabalho foram instituídas, a produção em massa exigia especialização na concepção de maquinários, no longo prazo, essas evoluções provaram ser uma das inovações mais radicais de todos os tempos.

O período de 1859-1874, por exemplo, foi caracterizado como um dos mais frutíferos e densos em inovação da história (MOKYR, 2010, p. 28). É difícil quantificar e testar tais afirmações, diz Mokyr (2010, p. 28), mas quase todas as novas técnicas desenvolvidas durante a primeira metade do século XX e muitas outras identificadas na Segunda Revolução Industrial foram originadas naquele período, dentre elas encontra-se um dos mais espetaculares avanços da segunda Revolução Industrial: a eletricidade. $O$ advento da eletricidade provocou mudanças nas formas de vida da sociedade por todos os benefícios que proporcionou, mudou a forma de produção industrial e, principalmente, mudou as bases de conhecimento da comunidade cientifica por exigir uma tecnologia que propiciasse sua distribuição, promovendo com isso aproximação e cooperação entre vários tipos de cientistas, experts e empreendedores, inventores práticos sem necessariamente conhecimento teórico, mas com uma boa noção do que iam fazer e investidores dispostos a investir no evento (CORSATTO, 2016; DRUCKER, 1993; MOKYR, 2010).

2.1.4 O período que segue após esses eventos e que vai até 1914

Perspectivas em Gestão \& Conhecimento, João Pessoa, v. 6, n. 2, p. 4-31, jul./dez. 2016 
O quarto período histórico considerado significativo para a transição e evolução das mudanças tecnológicas, inovações e seus impactos na produção do conhecimento organizacional segue até 1914. Entre 1860 e 1914, por exemplo, no período de transição no qual ocorrem a primeira e a segunda Revolução Industrial surge "uma onda de inovações radicais e avanços técnicos e conceituais considerados os mais espetaculares do que talvez em qualquer época da história." (MOKYR, 2010, p. 28). Considerando a transição que ocorreu entre 1860 e 1914, Mokyr (2010) afirma que neste período o mundo experimentou mudanças consideráveis, com grandes inovações radicais, envolvendo máquinas e equipamentos de diversas naturezas e utilidades que alteraram a ordem social do mundo ocidental tendo sido considerado o período mais revolucionário e inovador da história. Tais eventos e o desenvolvimento tecnológico, no entanto, se tornaram mais visíveis a partir dos séculos XIX e XX e seus impactos na economia e na sociedade se consolidaram e se mostraram diferentes dos acontecimentos anteriores, como se vê: "[...] such a world would have been different in some visible ways from the world of 1800, but not nearly as spectacularly different as the world of 1860 turned out to differ from that of 1914" (MOKYR, 2010, p. 28).

No período que compreendeu o final da primeira Revolução Industrial e a segunda Revolução Industrial que vai de 1860 a 1914, ocorreu uma cascata de inovações, particularmente com os dispositivos capazes de tirar proveito da energia elétrica. Muitas outras inovações radicais ou incrementais surgiram neste período, entre elas o desenvolvimento do motor a combustão interna compartilhado com as características do aço e da eletricidade (MOKYR, 2010, p. 33).

Outro elemento considerado de fundamental importância na segunda Revolução Industrial e que teve impactos significativos na produção do conhecimento e na geração de inovação foi a química, observe-se que, enquanto ferro e aço não necessitavam de informações científicas altamente elaboradas por se tratar de uma ciência empírica, para a química uma base epistêmica mais ampla de conhecimentos se tornou essencial e também se fez necessária uma ampla compreensão dos princípios envolvidos na exploração de novas técnicas, muitas delas derivadas de tentativas e erros, conta Mokyr (2010, p. 30). Na visão de Mokyr (2010, p. 38) a expansão gradual do conhecimento útil que fez sucesso no ocidente, possibilitou o surgimento de instituições que se dedicaram a desenvolver e disponibilizar ou mesmo comercializar o conhecimento e possibilitou também a evolução das indústrias de manufaturas que graças à eletricidade e ao motor a combustão evoluíram tecnologicamente no que se refere aos processos produtivos, aumentando sua capacidade de produção em massa e desenvolvendo novos métodos de comercialização.

Historicamente o caminho da evolução tecnológica, do conhecimento e da inovação contém todos esses elementos, as técnicas foram melhorando gradualmente por meio de microinvenções cumulativas, combinações com outras técnicas e foi neste período que as discussões no campo da tecnologia, da inovação e da utilização do conhecimento nas organizações evoluíram, particularmente entre as comunidades acadêmicas e de pesquisa, fortalecendo a estrutura do conhecimento tecnológico, inovativo e organizacional e seus processos.

2.2 Dos estudos das mudanças tecnológicas e da inovação e a dinâmica da evolução na produção do conhecimento organizacional ocorridas a partir do século XX, na visão de Dosi e Nelson (2010)

Em sequência à apresentação da evolução histórica das mudanças técnicas e tecnológicas e seus impactos na produção do conhecimento organizacional para a geração de inovações ocorridas período de 1750-1914, apresenta-se o avanço das mudanças tecnológicas

Perspectivas em Gestão \& Conhecimento, João Pessoa, v. 6, n. 2, p. 4-31, jul./dez. 2016 
e da dinâmica da evolução na produção do conhecimento ocorridas a partir do século XX com foco nos processos de produção do conhecimento organizacional para a geração da inovação.

No primeiro período (1750 a 1914) foram abordados alguns eventos que tiveram maior importância para o desenvolvimento econômico do período e suas formas de evolução da aprendizagem e produção do conhecimento para a geração de inovações. Nesta etapa, serão abordados os temas referentes à evolução histórica da inovação e suas contribuições para o conhecimento organizacional, observando a inovação tecnológica, sob o aspecto central do processo evolutivo e da cumulatividade. Ressalta-se que Schumpeter (1883-1950) trouxe a inovação com abordagem tecnológica para o centro do debate sobre o desenvolvimento econômico e os economistas neoschumpeterianos Foray e Lundvall (1996), Freeman (1974), Dosi e Nelson (2010), Nelson e Winter (1982) e a Organização para a Cooperação e Desenvolvimento Econômico (2005) entre outros ampliaram esta abordagem, inserindo a importância do conhecimento no contexto da inovação (FIGUEIREDO, 2015).

Considerando estas discussões, faz-se uma revisão da abordagem de Dosi e Nelson (2010) sobre o tema. Nesse contexto, Dosi e Nelson (2010), defensores da proposta evolucionista, trazem a discussão sobre a incorporação implícita dos mecanismos de mudança na inovação tecnológica, econômica e social proporcionadas pelo caráter dinâmico da tecnologia nas novas teorias de crescimento econômico e apresentam as premissas básicas de revisão e integração do que foi aprendido sobre os processos da evolução tecnológica e suas principais características evolucionistas. De acordo com Dosi e Nelson (2010) três perspectivas são fundamentais para a construção da aprendizagem e do conhecimento organizacional, e estão relacionadas à natureza da tecnologia, aos aspectos de como as tecnologias evoluem e do ponto de vista da concorrência schumpeteriana e seus impactos na dinâmica industrial. Nesta abordagem, Dosi e Nelson (2010, p. 56) situam a inovação como "um processo dependente da trajetória, por meio da qual o conhecimento e a tecnologia são desenvolvidos a partir da interação entre vários atores e fatores." A estrutura dessa interação afetou a trajetória futura da mudança econômica, de forma que, em termos gerais ao abordar o primeiro item que caracteriza a natureza da tecnologia observa-se que ela é um projeto que demanda conhecimentos humanos, executado com fins específicos, cuja execução está vinculada ao acesso a partes específicas do conhecimento que, por sua vez, está aportado nas informações, receitas, rotinas e processos, os quais estão submetidos às tecnologias e às inovações (DOSI; NELSON, 2010).

Neste contexto, conforme os autores, a produção do conhecimento organizacional para a geração de inovações começa a levar em consideração a importância da utilização da informação como um input que leva à compreensão da natureza e da dinâmica do conhecimento, de como ele é "expressado, armazenado e incrementado" (DOSI; NELSON, 2010, p. 59) e transformado em receitas. Estas por sua vez, representam um conjunto de procedimentos e ações que precisam ser tomadas para alcançar determinados resultados. Tais conhecimentos registrados em forma de processos e receitas, conforme Dosi e Nelson (2010, p.61) evoluem para a execução de um conjunto de rotinas que se caracterizam pela capacidade que uma organização adquire para executar em algum contexto o que está registrado e foi apreendido, obtendo resultados no seu desempenho. Esta capacidade de execução é de natureza humana, executada pelas pessoas, por vezes de forma tácita e, requer, portanto, um conjunto de competências e capacidades específicas para sua execução (DOSI; NELSON, 2010; TEECE, 2010).

Esta teoria caracteriza a identificação técnico-econômica dos produtos finais por um lado e das máquinas, equipamentos, componentes e produtos intermediários de outro, estando diretamente relacionada, segundo Dosi e Nelson (2010, p. 63) ao conhecimento, aos procedimentos e à relação com os inputs e outputs abordando neste fator discussões sobre a junção complementar das informações, receitas, rotinas e resultado final. Neste aspecto, nota-

Perspectivas em Gestão \& Conhecimento, João Pessoa, v. 6, n. 2, p. 4-31, jul./dez. 2016 
se que, numa visão dos processos da tecnologia, a partir do século $X X$, o foco principal de orientação para o desenvolvimento de um produto passa a ser, antes que a lista de insumos utilizados na sua execução, a concepção dos dispositivos e procedimentos que caracterizam o processo de evolução das tecnologias e seus resultados de inovação, com processos, receitas e rotinas previamente definidos que evoluem de forma dinâmica para a produção e utilização do conhecimento organizacional (FORAY; LUNDVALL, 1996; DOSI; NELSON, 2010).

Assim, a segunda questão apresentada pelos autores está relacionada à observação da forma de como as tecnologias evoluem e, afirmam Dosi e Nelson (2010, p. 64-65) os processos pelos quais as tecnologias evoluem são diferentes em aspectos importantes na sua evolução, projetos voltados aos estudos da evolução da biologia, por exemplo, são diferentes dos projetos voltados aos estudos das engenharias, no mundo contemporâneo, muitas tecnologias estão associadas a campos específicos das ciências aplicadas ou engenharias e, a forma como as tecnologias evoluem impactam nas formas de produção do conhecimento e o inverso também é verdadeiro.

Para Dosi e Nelson (2010, p. 66) as tecnologias evoluem de diversas formas, entre elas, os autores apontam para os paradigmas tecnológicos e trajetórias tecnológicas, onde, um paradigma incorpora uma visão, uma definição dos problemas relevantes a serem abordados e os padrões de questionamentos a serem elaborados para resolvê-los. Isso implica uma visão das supostas necessidades dos usuários e dos atributos que eles valorizam para os produtos ou serviços demandados, envolvendo conhecimentos e princípios científicos e técnicos relevantes para o desenvolvimento desses produtos ou serviços e definições sobre quais as tecnologias específicas a serem empregadas na tarefa (DOSI; NELSON, 2010, p. 67), pode-se dizer que tais paradigmas e trajetórias estão associados às formas de condução da evolução das tecnologias, metodologias e conhecimentos aplicados para as inovações desenvolvidas. As características dos paradigmas tecnológicos e as características das trajetórias tecnológicas fazem parte dos esforços para impulsionar o avanço tecnológico e canalizar esses avanços ao longo de trajetórias tecnológicas distintas, desta forma, a mudança de um paradigma geralmente implica em mudança da trajetória (DOSI; NELSON, 2010, p.70). Outra forma de evolução de tecnologias apresentada pelos autores são as oportunidades tecnológicas, estas, afirmam Dosi e Nelson (2010, p. 70) se referem ao processo de acumulação de conhecimento, ou seja, sua cumulatividade, nesse contexto os autores reconhecem a natureza do conhecimento subjacente através dos diversos campos como elemento gerador de oportunidades dos avanços técnicos que embora sejam diferentes à medida que o conhecimento é adquirido, ele se acumula a partir da experiência operacional e gera um processo de desenvolvimento de novos conhecimentos ou novas tecnologias a partir da cumulatividade.

De acordo com Dosi e Nelson (2010, p.73) a cumulatividade captura a natureza incremental da pesquisa tecnológica e, crucialmente varia bastante entre diferentes atividades inovativas. A esse respeito, há uma instância bastante difundida, do conhecimento baseado na dinâmica dos retornos crescentes que leva ao terceiro fator avaliado por Dosi e Nelson (2010, p. 73) que aborda as questões da demanda e outros fatores sócio-econômicos que moldam a direção do avanço tecnológico, esses fatores dizem respeito às demandas geradas pelo mercado, pelo usuário ou por outros fatores socioeconômicos, avaliando as tendências de uma tecnologia para seguir uma trajetória específica e os fatores que impactam esta tendência.

A tendência do avanço de uma tecnologia para seguir uma trajetória, dizem os autores, não é necessariamente a indicação de que as necessidades e preferências do usuário e as condições econômicas como aquelas relativas aos preços, por exemplo, não afetarão o caminho do desenvolvimento tecnológico. Outra abordagem de Dosi e Nelson (2010) sobre a forma de evolução das tecnologias diz respeito aos meios de apropriação que contribuíram e contribuem ainda hoje para a evolução tecnológica, para os autores entre esses meios estão:

Perspectivas em Gestão \& Conhecimento, João Pessoa, v. 6, n. 2, p. 4-31, jul./dez. 2016 
a utilização de pesquisa e desenvolvimento; cumulatividade; apropriação de conhecimentos em regimes evolucionistas que permitem apropriação do progresso técnico e as patentes que por sua vez indicam a evolução tecnológica. Dosi e Nelson finalizam sua abordagem sobre a forma como as tecnologias evoluem apontando como último fator que contribui para esta questão os avanços tecnológicos e a teoria da firma. Ressalta-se que firmas são entidades econômicas que grosso modo empregam novas tecnologias, produzem e comercializam novos produtos, operam com novos processos produtivos e por conseguinte operam com inovações (DRUCKER, 1993; DOSI; NELSON, 2010). Essa é a característica dos modelos de negócio do capitalismo moderno, onde as empresas se tornaram o locus central dos esforços para os avanços tecnológicos (DOSI; NELSON, 2010, p. 81) sendo caracterizadas, segundo os autores pelos padrões de ação rotineiros que vão se modificando ao longo do tempo por orientações estratégicas.

Ao trazer à tona as discussões sobre as bases de conhecimento, Dosi e Nelson (2010) retomam as discussões sobre a dinâmica da inovação e seus estudos, observando-a como um processo que envolve experimentação, modificações e melhoramentos das características de desempenho dos componentes do sistema inovativo e, ainda a adaptação de processos que conduzem às mudanças incrementais $e$ às rupturas mais radicais na estrutura e funcionalidades dos artefatos, dos novos arranjos organizacionais, levando a uma nova percepção das teorias evolutivas da inovação (DOSI; NELSON, 2010; FIGUEIREDO, 2015).

Se, ao tempo em que afirmam que a tecnologia de modo geral pode ser vista "como um projeto humano executado para determinados fins [...]" (DOSI; NELSON, 2010, p. 56), os autores questionam sobre quais seriam as características do conhecimento tecnológico, podese inferir que tal reflexão está relacionada aos processos de aprendizagem específicos e fontes específicas de geração de conhecimento e inovações estruturais. É provável que este seja um contraponto da dinâmica da evolução industrial a partir da visão schumpeteriana, cuja teoria econômica está "[...] fundamentada na incorporação de inovações ao sistema econômico, isto é, as mudanças econômicas são resultados das interações e/ou impactos, por exemplo, das inovações tecnológicas no sistema econômico" (TAVARES et al., 2005, p. 105), ou seja, o foco central passou a ser no resultado da incorporação das inovações e seus impactos no desenvolvimento econômico, concorrência e mercado.

Considerando estas questões, Dosi e Nelson (2010, p. 96), elencaram a concorrência schumpeteriana como sendo o terceiro fator de contribuições históricas ocorridas a partir do século XX. Para os autores, concorrência schumpeteriana é o processo pelo qual firmas heterogêneas competem com base nos produtos e serviços que oferecem, observando como algumas empresas crescem e outras declinam, saindo do mercado e ainda algumas novas surgem acreditando que podem ser bem-sucedidas na sua competição.

Para evidenciar as características da concorrência industrial na visão schumpeteriana, os autores propõem a avaliação das estruturas empresariais e características das empresas abordando variáveis como: a) a heterogeneidade microeconômica: começando com o tamanho; b) taxa de crescimento corporativo e rentabilidade corporativa; c) por traz das performances heterogêneas: inovação e produção eficiente; d) capacidade corporativa; competição e mudança industrial; e) dinâmica específica da indústria e seus ciclos de vida e; f) modelos de dinâmicas industriais (DOSI; NELSON, 2010, p. 111). Considerando tais características sob a visão histórica da evolução industrial nos processos inovativos e sua dinâmica no tempo, observa-se a importância das contribuições schumpeterianas e os reforços que a visão neoshumpeteriana trouxe aos estudos dos avanços teóricos e empíricos, defendendo a inovação como fator determinante do processo dinâmico da economia e ainda, "fundamental para a definição dos novos paradigmas de competitividade econômica, especialmente no atual crescimento da competitividade em nível regional e global." (TAVARES et al., 2005, p. 106).

Perspectivas em Gestão \& Conhecimento, João Pessoa, v. 6, n. 2, p. 4-31, jul./dez. 2016 
A proposta e teorias com abordagem no desenvolvimento das tecnologias e inovação avançaram na sua concepção ao longo do século $X X$, de forma que a utilização do conhecimento se tornou cada vez mais evidente e necessária no campo das dinâmicas organizacionais, a percepção da inovação de cunho tecnológico em suas visões estritamente economicista avançaram para as teorias evolucionistas, inserindo um conjunto de variáveis de cunho sistêmico, dando corpo ao paradigma das inovações evolucionistas. Nelson e Winter (1982) foram pioneiros em defender argumentos evolucionistas, os autores mencionavam que a inovação é um processo dependente da trajetória na qual o conhecimento e a tecnologia são desenvolvidos em sua interação entre vários atores e fatores, essa abordagem estabeleceu novas trajetórias voltadas para a difusão de conhecimentos e atuação sistêmica, este aspecto, considera como atores externos, as instituições públicas ou privadas, além dos fatores comportamentais e sociais. Esta abordagem, que traz a visão da inovação como um sistema, que segundo Lundvall (1992) e Nelson (1993), apresentada no Manual de Oslo, em sua terceira edição, estuda:

[...] a influência das instituições externas, definidas de forma ampla, sobre as atividades inovadoras das empresas. Ela enfatiza a importância da transferência e da difusão das ideias, experiências, conhecimentos, informações e sinais de vários tipos. Os canais, as redes de comunicação pelas quais essas informações circulam inserem-se numa base social, política e cultural que guia e restringe as atividades e capacitações inovadoras. (ORGANIZAÇÃO PARA A COOPERAÇÃO E DESENVOLVIMENTO ECONÔMICO, 2005, p. 41).

Pode-se considerar tal abordagem como um marco para o processo de inovação nas organizações/empresas e no mercado uma vez que ela altera "[...] o foco das políticas em direção a uma ênfase na interação entre instituições e observam processos interativos na criação, difusão e aplicação de conhecimentos" (ORGANIZAÇÃO PARA A COOPERAÇÃO E DESENVOLVIMENTO ECONÔMICO, 2005, p. 41).

Esta visão redireciona o olhar sobre as formas de atuação na difusão e apropriação de conhecimento para o desenvolvimento da inovação nas organizações no século $X X$, alterando não só o foco dos direcionamentos da aprendizagem e da produção do conhecimento, mas também o paradigma da gestão organizacional, conforme assinalado por Peter Drucker (1993), que traz à discussão a mudança de paradigma para a gestão organizacional e para a mudança do locus da inovação, transmutando-o para o conhecimento e para as pessoas detentoras desse conhecimento em uma organização. Drucker (1993) ao enfatizar a função da organização como um composto de especialistas que trabalham em conjunto, com o propósito de tornar produtivos os conhecimentos uma vez que são eles os geradores de inovação, traz a visão de que "o recurso econômico básico - os meios de produção - para usar uma expressão dos economistas" como ele diz, deixou de ser o capital e a mão de obra e passou a ser o conhecimento, onde "[...] o valor é criado pela produtividade e pela inovação, que são aplicações do conhecimento ao trabalho." (DRUCKER, 1993, p. 3).

Considerando a colocação de Drucker (1993) observa-se que a proposta de aplicação do conhecimento ao trabalho se torna evidenciada no decorrer do século XX e avança para 0 século XXI, assim como se dá a evolução das tecnologias para a inovação conforme apresentado por Dosi e Nelson (2010). As abordagens são extensas e os estudos históricos apontam para uma evolução contínua dos processos de produção de conhecimentos e aprendizagem organizacional, desta forma, complementa-se a compreensão desta abordagem com os conceitos de tecnologia, inovação e produção de conhecimentos desta natureza.

Perspectivas em Gestão \& Conhecimento, João Pessoa, v. 6, n. 2, p. 4-31, jul./dez. 2016 


\section{TECNOLOGIA E INOVAÇÃO: CONCEITOS E PRODUÇÃO DO CONHECIMENTO DA MESMA NATUREZA}

Dando continuidade à abordagem dos estudos das mudanças técnicas e da inovação e a dinâmica da evolução na produção do conhecimento organizacional ocorridas a partir de 1914, adentrando para o século XX, traz-se os conceitos e definições de tecnologia e inovação e suas interações com a produção do conhecimento buscando esclarecer as características dos conhecimentos produzidos e sua importância para a inovação.

Neste aspecto, vale observar que, o que se tem no primeiro período apresentado, conforme apontam os registros históricos, é a utilização do conhecimento tácito, que produz mudanças de cunho técnico, um período onde grande parte das invenções, aparatos e equipamentos com nuances tecnológicas foram desenvolvidos por artesãos, contando apenas com suas habilidades técnicas sem compreensão de como poderiam ser reproduzidos ou melhorados, já que as técnicas informais da era pré-industrial eram limitadas e a capacidade técnica e habilidade dos artesãos afetava a produtividade. As dificuldades ou gargalos conforme Mokyr (2010) as definia, se manifestavam quando da necessidade de adaptar uma técnica à outra para construir algo inteiramente diferente onde se fazia necessário um conhecimento complementar e preciso da natureza dos processos, essa ignorância, por sua vez, não impediu o avanço do desenvolvimento de novos equipamentos (MOKYR, 2010, p. 16).

Diante disto, a partir do século XIX, considerando as possibilidades de explicação da evolução das tecnologias por meio de registros das suas ocorrências e dos processos de transformação que envolve em si um conjunto de atividades e de processos, a tecnologia passou a ter seu desenvolvimento vinculado à produção do conhecimento das mais diversas naturezas aportado nas pessoas, instituições e organizações, podendo ser definida como "[...] um conjunto de conhecimentos científicos e empíricos, de habilidades, experiências e organização requeridos para produzir, distribuir, comercializar e utilizar bens e serviços" (SÃENZ; CAPOTE, 2002, p. 47). Esta construção de conhecimentos caracterizados como tecnológicos inclui tanto conhecimentos tácitos, teóricos, práticos, meios físicos, métodos, processos produtivos, gerenciais e organizacionais, como as receitas e rotinas que compõe os inputs e outputs para a geração de inovações (FORAY; LUNDVALL, 1996; NELSON; DOSI, 2010; SÃENZ; CAPOTE, 2002). Uma ampliação do conceito apresentada por Rocha (1996, p. 13) diz que "submetido a um critério combinado de utilidade e de base técnico-científica, a tecnologia surge como um novo sistema simbólico ou como uma cultura, com linguagem e determinações próprias" onde estão envolvidos não só o conhecimento tecnológico embutido nos produtos, processos, máquinas, mas também o 'saber fazer', uma aprendizagem que extrapola os bens e os meios utilizados para produzi-los (DRUCKER, 1993; ROCHA, 1996).

Ainda na proposta de conceituar tecnologia, vinculando-a às formas de produção do conhecimento, tem-se a abordagem de Figueiredo $(2015$, p. 14) que resgata a visão de Keith Pavitt de que "tecnologia deveria ser compreendida como um quantum de conhecimento retido por pessoas e organizações." Conforme o autor, este "conhecimento, resultante da experiência acumulada em projeto (design) é, em sua maioria, tácito" (FIGUEIREDO, 2015, p. 14), ou seja, "não está formatado, em sua totalidade, em nenhum tipo de manual ou software." (FIGUEIREDO, 2015, p. 15).

Considera-se que os conceitos apresentados são similares em sua formulação, na medida em que tratam a tecnologia como processos que envolvem projetos, produtos/bens e serviços que são, em parte "codificadas na forma de manuais de operação, produtos, equipamentos, publicações técnicas e científicas" (FIGUEIREDO, 2015, p. 14) e em parte vinculadas às pessoas, ao 'saber fazer', preservando certo grau de tacitividade. Assim, no que se refere à concepção da produção do conhecimento tecnológico, pode-se dizer que nas abordagens apresentadas, a produção do conhecimento tecnológico consiste em buscar

Perspectivas em Gestão \& Conhecimento, João Pessoa, v. 6, n. 2, p. 4-31, jul./dez. 2016 
formas de documentar e aplicar o conhecimento adquirido para, entre outras atividades, melhorar procedimentos e rotinas que conduzam a fins práticos e geração de inovações em busca de resultados. Nesta perspectiva, Dosi e Nelson (2010) trazem a abordagem da incorporação implícita dos mecanismos de mudança e inovação tecnológica, econômica e social e seus impactos nas novas formas de produção do conhecimento afirmando que a "produção de qualquer artefato ou a realização de qualquer serviço geralmente envolve sequências de ações cognitivas e físicas e uma série de aspectos relacionados aos conhecimentos, habilidades e atitudes de seus executores" (DOSI; NELSON, 2010, p. 62).

Conforme os autores "[...] the procedure involves a notion of design, the later is in general only one of them any possible configurations which can be achieved on the grounds of any one knowledge base" (DOSI; NELSON, 2010, p. 62), com esta abordagem, os autores trazem à tona as discussões sobre os fundamentos das bases de conhecimento utilizadas em projetos e retomam as discussões sobre a as possíveis configurações que o conhecimento alcança no contexto organizacional para a geração de inovação.

Assim, ao se falar em inovação e seus conceitos, considerando esta abordagem e os entendimentos encontrados na literatura pode-se inferir que sua evolução segue uma trajetória ao longo do tempo tanto no que se refere à compreensão de que "o conhecimento em todas as suas formas desempenha um papel fundamental no progresso econômico e a inovação é um fenômeno complexo e sistêmico." (ORGANIZAÇÃO PARA A COOPERAÇÃO E DESENVOLVIMENTO ECONÔMICO, 2005, p. 21) como na compreensão de 'o que é inovar' e como se dá esta dinâmica nas empresas/organizações. Neste aspecto, tem se que inovação é considerada na sua essência como um processo de dimensão econômica e social envolvendo as fronteiras do conhecimento, seja ele tecnológico ou não, tendo como foco principal manter a competitividade e a sustentabilidade socioeconômica de uma empresa no mercado, conforme se pode observar nas abordagens e conceitos apresentados na literatura sobre 0 tema que são os considerados usuais e reconhecidos nos âmbitos acadêmico, científico e organizacional.

Apesar do tema inovação se fazer presente desde o início das discussões históricas sobre o desenvolvimento econômico, particularmente o da indústria, como se pode observar nos relatos da evolução histórica, das mudanças técnicas, tecnológicas e seus avanços para o desenvolvimento das inovações, foi Schumpeter $(1911 ; 1950)$ que se destacou como estudioso dos fenômenos econômicos entre eles a importância da inovação na economia. O pensamento do economista teve influência significativa nas teorias da inovação de cunho tecnológico, por inserir o tema na sua teoria econômica e por consequência no sistema econômico, enfatizando as questões do desenvolvimento econômico, com foco no mercado. Conforme Schumpeter $(1985$, p. 76) inovação é:

1) Introdução de um novo bem - ou seja, um bem com que os consumidores ainda não estiverem familiarizados - ou de uma nova qualidade de bem. 2) Introdução de um novo método de produção, ou seja, um método que ainda não tenha sido testado pela experiência no ramo próprio da indústria de transformação, que de algum modo precisa ser baseada numa descoberta cientificamente nova e, pode consistir também em nova maneira de manejar comercialmente uma mercadoria. 3) Abertura de um novo mercado, ou seja, de um mercado em que o ramo particular da indústria de transformação do país em questão não tenha ainda entrado, quer esse mercado tenha existido antes, quer não. 4) Conquista de uma nova fonte de oferta de matérias-primas ou de bens semimanufaturados, mais uma vez independentemente do fato de que essa fonte já existia ou teve que ser criada. 5) Estabelecimento de uma nova organização de qualquer indústria,

Perspectivas em Gestão \& Conhecimento, João Pessoa, v. 6, n. 2, p. 4-31, jul./dez. 2016 
como a criação de uma posição de monopólio (por exemplo, pela trustificação) ou a fragmentação de uma posição de monopólio.

Ainda, diante da possibilidade do novo ou daquilo que pode passar por transformações significativas, Schumpeter (1961) definiu a inovação como um processo de destruição criadora, onde a dinâmica do mercado leva empresas à destruição, recriação ou adaptação de processos, produto, serviços e métodos com vistas à conquista do mercado. (SCHUMPETER, 1961). O pensamento schumpteriano se propagou pelo mundo e ainda hoje ao se falar em inovação recorre-se a ele. Conforme Figueiredo (2015, p. 21) Schumpeter (1883-1950) não só trouxe à discussão "[...] uma perspectiva ampliada de inovação envolvendo imitação, experimentação, adaptação de processos e de produtos, novos arranjos organizacionais, novas fontes de energia e matérias-primas, assim como P\&D" como trouxe a "noção de inovação como recombinação de conhecimentos ou tecnologias existentes" (FIGUEIREDO, 2015, p. 21). O pensador deixou um séquito de seguidores denominados neoschumpeterianos que avançaram nos conceitos e entendimentos dos processos de inovação. Entre eles, aponta-se Freeman (1974), Nelson e Winter (1982) e Dosi (1984) cujas abordagens trazem, em linhas gerais, as questões dos paradigmas, trajetórias e estratégias tecnológicas com foco no mercado e cujos conceitos e definições de inovação, ao se referirem à produção de bens e serviços estão voltados para as questões tecnológicas e sua evolução para o conhecimento, embora apresentem uma visão mecanicista e economicista.

Já com uma proposta mais abrangente, saindo do escopo da teoria mecanicista ou economicista, sem, no entanto, desconsiderar sua importância, o Manual de OSLO, uma das principais bibliografias sobre o tema, considerando as mudanças estruturais e sistêmicas pelas quais as empresas vêm passando, ampliou a abrangência do sentido da inovação inserindo no seu escopo as inovações de marketing e organizacional. Estas mudanças foram incluídas na terceira edição do Manual a partir da percepção "crescente de que muita inovação no setor de serviços não é apreendida de maneira adequada pelo conceito de tecnologias, processos e produtos." (ORGANIZAÇÃO PARA A COOPERAÇÃO E DESENVOLVIMENTO ECONÔMICO, 2005, p. 11). Entende-se com isso que inovações advindas de setores intensivos em conhecimento precisavam ser inseridas no contexto da medição, além da necessidade de incluir os países em desenvolvimento no contexto das pesquisas em inovação.

Tais alterações tiveram a finalidade de ampliar as formas de mensuração e incluir os países com diferentes cenários econômicos e sociais no processo de medição, desta forma, o Manual de Oslo assume que inovação é:

[...] a implementação de um produto (bem ou serviço) novo ou significativamente melhorado, ou um processo, ou um novo método de marketing, ou um novo método organizacional nas práticas de negócios, na organização do local de trabalho ou nas relações externas. (ORGANIZAÇÃO PARA A COOPERAÇÃO E DESENVOLVIMENTO ECONÔMICO, 2005. p. 55).

Neste contexto, em se tratando de conceitos de inovação e suas interações com a produção do conhecimento útil gerado nas organizações para esta finalidade, observa-se que no final do século XX e no decorrer do século XXI com o processo de globalização da economia, as empresas passaram e ainda passam por transformações estruturais, conjunturais, sociais e comportamentais que provocaram alterações na sua natureza e nos modelos de negócios colocando a inovação em um patamar de importância que a torna cada vez mais necessária e presente, estimulando revisões e trazendo novas abordagens e conceitos para o tema.

Perspectivas em Gestão \& Conhecimento, João Pessoa, v. 6, n. 2, p. 4-31, jul./dez. 2016 
Considerando estas abordagens que vinculam a inovação à produção do conhecimento organizacional, Peter Drucker (1993), no século vinte traz o conceito da sociedade do conhecimento e das mudanças no contexto da utilização do conhecimento que deixa se ser aplicável ao 'ser', passando da noite para o dia a ser aplicado ao fazer (DRUCKER, 1993), e ainda conforme o autor essa "aplicação do conhecimento ao trabalho criou economias desenvolvidas ao provocar uma explosão de criatividade" (DRUCKER, 1993, p. 19), impulsionando a utilização do conhecimento e a geração de inovações no decorrer dos séculos XIX e XX. Diante do exposto, tem-se a percepção de que importância do aproveitamento do conhecimento útil criado em uma empresa/organização se consolidou assim como sua utilização nos processos de geração de inovação, autores como Davila et al. (2007), Tidd et al. (2008) e Feldman e Kogler (2010) por exemplo, corroboram com a abordagem de Drucker (1993) vinculando o processo de inovação ao conhecimento e à criatividade. Para Davila et al. (2007, p. 27) as empresas/organizações desenvolvem seu "próprio tipo de inovação mediante o acréscimo de toques especiais (por exemplo, cultura, conhecimento específico, recompensas diferenciadas) - mesmo que os ingredientes básicos para a inovação sejam praticamente iguais", Tidd et al. (2008, p. 35) dizem que a inovação cria "novas possibilidades por meio de combinações de diferentes conjuntos de conhecimentos" os autores defendem que os conhecimentos úteis gerados em uma empresa/organização se apresentam na maioria das vezes como conhecimento "tácito, técnico, empírico, podendo já existir, ser fruto de uma experiência ou pode ser resultado de um processo de busca por tecnologias, mercados, ações da concorrência etc." (TIDD et al., 2008, p. 35). Feldman e Kogler, por sua vez, mencionam que "a inovação é a capacidade de misturar e tecer diferentes tipos de conhecimentos, transformando-os em algo novo, diferente e que tenha valor econômico", afirmam ainda que "semelhante à arte, a inovação é uma expressão criativa." (FELDMAN; KOGLER, 2010, p. 382).

Considerando as proposições e abordagens apresentadas por Davila et al. (2007), Tidd et al. (2008) e Feldman e Kogler (2010) pode-se considerar que elas estão em consonância com a afirmação de Drucker (1993), no início da década de 1990 na qual o conhecimento adquire importância, significado e aplicação diferentes daqueles utilizados até então tendo como "ponto central a mudança da produção" que passou "quase da noite para o dia, do artesanato para a tecnologia" (DRUCKER, 1993, p. 11), resultando na "aplicação do conhecimento ao trabalho" ainda conforme Drucker (1993) transformando o conhecimento em um recurso essencial, cujas novas formas de produção, utilização, retenção e aplicação impactam nos processos de inovação nas empresas/organizações.

\section{A PRODUÇÃO DO CONHECIMENTO ORGANIZACIONAL, SUA IMPORTÂNCIA NO PROCESSO DE INOVAÇÃO E SUAS CONEXÕES COM AS FORMAS DE APRENDIZAGEM ORGANIZACIONAL: AS LEARNING ORGANIZATION E A PRÁTICA DO OPEN USER INNOVATION}

Tendo em vista as questões históricas e conceituais sobre a evolução da tecnologia e inovação abordadas, esta parte do artigo tem como proposta principal apresentar as questões relativas à produção do conhecimento organizacional, sua importância no processo de inovação e suas conexões com o processo de aprendizagem organizacional utilizando como base a proposta da learning organization e open user innovation, observando os fatores de aprendizagem e conhecimento organizacional que estimulam os processos inovativos nas empresas e que estão aportados prioritariamente nas pessoas, nos processos e nos resultados produzidos (sejam eles produtos ou serviços), ou seja, nas entradas (inputs) e nas saídas (outputs). Entende-se que neste contexto ocorre a convergência e a conversão do conhecimento incorporado nas receitas, rotinas e artefatos tecnológicos, cuja realização processual está suportada nos procedimentos centrais que integram a natureza do conhecimento às rotinas da produção deste conhecimento que, por sua vez, estimulam as

Perspectivas em Gestão \& Conhecimento, João Pessoa, v. 6, n. 2, p. 4-31, jul./dez. 2016 
inovações (DOSI; NELSON, 2010; FORAY; LUNDVALL, 1996).

Desta forma, no que se refere à produção do conhecimento organizacional e sua importância no processo de geração de inovações, pode-se dizer que este é um processo recente na teoria das organizações e que ainda existem lacunas a serem preenchidas na compreensão da forma como como se desnvolvem os construtos da sua criação em uma organização (FORAY; LUNDVALL, 1996; MORESI, 2001; NOGUEIRA; ODELIUS, 2015).

Pode-se afirmar, no entanto, que sua construção é sistematica, pois trata de compreender o fenômeno de sua criação como um todo e explícita e intencional na medida em que envida esforços para aplicá-lo, buscando maximizar a eficiência do capital intelectual instalado e utilizado em uma organização (MORESI, 2001; STEWART, 1998).

Assim, tem-se que tais esforços evoluiram tácita e empiricamente considerando as necessidades das organizações em desenvolver suas inovações nas mais variadas dimensões, impulsionadas pela globalização que proporcionou a facilidade de acesso a métodos e ferramentas para a produção do conhecimento que é reconhecido como "um dos principais fatores geradores de inovação e, considerando ainda algumas das diversas formas de produção do conhecimento existentes na literatura, que serviram como guia para as novas formas de produção do conhecimento organizacional" (CORSATTO; HOFFMANN, 2015, p. 13).

Diante disto, ao se abordar a relação entre conhecimento e inovação, traz-se as visões apresentadas por alguns autores na última década do século XX e início do século XXI sobre o tema. Peter Drucker (1993), Davenport e Prusak (2003), Nonaka e Takeuchi (2008), Choo (2006) entre outros, trouxeram o tema conhecimento para o contexto organizacional, Tidd et al. (2008) evoluíram sua abordagem para o contexto da inovação como uma questão de conhecimento e vantagem competitiva.

Para Drucker (1993), que aborda a evolução histórica da sociedade em cento e cinquenta anos, no período de 1750 a 1900, afirma que "[...] nem o capitalismo, nem as inovações tecnológicas eram novidades; ambos haviam sido fenômenos comuns e recorrentes através das idades tanto no ocidente como no oriente" (DRUCKER, 1993, p. 3) o que havia de novo era o conhecimento, o reconhecimento da importância do capital intelectual, a "velocidade da sua difusão e seu alcance global através de culturas e classes" (DRUCKER, 1993, p. 3) dando lugar ao que o autor chamou de sociedade pós-capitalista e sociedade do conhecimento. Neste contexto, o conhecimento se tornou "o recurso econômico básico" (DRUCKER, 1993, p. xvi) em uma sociedade onde as pessoas desempenham o principal papel no processo organizacional, onde o "conhecimento está sendo aplicado ao próprio conhecimento" (DRUCKER, 1993, p. 4) levando as organizações/empresas a se atentar para a necessidade de "aprender como inovar - e aprender que a inovação pode e deve ser organizada como um processo sistemático" (DRUCKER, 1993, p. 37) de produção e utilização do conhecimento organizacional.

Para Davenport e Prusak (2003) o conhecimento é de vital importância para uma organização, não sendo, portanto, nem puro nem simples, mas se constituindo em "uma mistura de vários elementos; é fluido; como também formalmente estruturado, é intuitivo e, portanto, difícil de colocar em palavras" (2003, p. 6), podendo ser compreendido "tanto como um processo quanto como um ativo" (DAVENPORT; PRUSAK, 2003, p. 6). Os autores descrevem como ponto forte do conhecimento a "velocidade, complexidade, senso histórico e de contexto, discernimento e flexibilidade" (DAVENPORT; PRUSAK, 2003, p. 17), elementos essenciais juntamente com a criatividade pessoal para a geração de inovações.

Apesar destas abordagens, entende-se que o processo de criação do conhecimento em uma organização é complexo e depende de vários fatores internos e externos, diante disso Foray e Lundvall (1996) defendiam existência de lacunas em relação à produção deste conhecimento e sua conversão em produtos, bens e serviços e consequentemente na geração

Perspectivas em Gestão \& Conhecimento, João Pessoa, v. 6, n. 2, p. 4-31, jul./dez. 2016 
de inovação, a percepção dos autores apontava para uma dinâmica entre o conhecimento tácito e o codificado.

Neste contexto, Nonaka e Takeuchi (2008), também atentos a esta lacuna propuseram uma nova teoria para a criação do conhecimento organizacional, uma vez quem, conforme os autores, a teorias existentes para esta finalidade não eram suficientes para explicar a geração da inovação a partir do conhecimento tal como ele estava sendo utilizado, diante disso, Nonaka e Takeuchi (2008) trouxeram foco para a utilização dos conhecimentos tácito e explícito para a geração da inovação.

Para os autores "existe uma outra forma de pensar o conhecimento e seu papel nas organizações empresariais" (NONAKA; TAKEUCHI, 2008, p. 40) que se contrapõe ao processo usual de aprendizagem organizacional que ocorre normalmente de um modo exógeno, onde a organização busca, avalia e processa a informação do ambiente externo para tomada de decisões que estejam de acordo as novas circunstâncias do mercado (CHOO, 2006; NONAKA; TAKEUCHI, 2008) e, embora essa visão justificasse o funcionamento de uma organização no que se refere ao conhecimento, conforme Nonaka e Takeuchi (2008) ela era limitada, uma vez que não explicava a inovação.

De acordo com Nonaka e Takeuchi (2008) embora muito se fale sobre a importância do conhecimento organizacional, "pouca atenção tem sido dada a como o conhecimento é criado e como o processo de criação é administrado" (NONAKA; TAKEUCHI, 2008, p. 57), assim, buscando explicar essas formas de criação do conhecimento, apresentaram sua teoria com base nas dimensões ontológica ${ }^{5}$ e epistemológica ${ }^{6}$. Na dimensão ontológica, grosso modo, Nonaka e Takeuchi (2008) tratam do conhecimento produzido pelos indivíduos que fazem parte da organização e na dimensão epistemológica tratam do conceito de conhecimento tácito e conhecimento explícito. De acordo com os autores o conhecimento tácito é "[...] aquele de âmbito pessoal, específico ao contexto e, por isso difícil de formalizar e o explícito ou 'codificado', por outro lado, se refere ao conhecimento que é transmissível na linguagem formal, sistemática." (NONAKA; TAKEUCHI, 2008, p. 57). Estes conhecimentos, por sua vez, interagem entre si nas suas mais diversas formas para criar o conhecimento organizacional. Essas formas denominadas por Nonaka e Takeuchi (2008) de modos de conversão, ocorrem por meio da observação da dinâmica do processo de socialização, externalização, combinação e internalização (SECI) que de acordo com os autores faz parte do núcleo do processo de criação do conhecimento.

Assim, a interação e combinação destes conhecimentos em uma organização e sua conexão com os processos de aprendizagem interno e externo para gerar inovação podem ocorrer observando as três dimensões da inovação e do conhecimento propostas por Kusunoki (2008, p. 145) quais sejam: i) a função know why que está diretamente vinculada ao aprendizado pelo estudo, experimentos e simulações que levam à compreensão do princípio de como as coisas funcionam, dos por quês fazer e, é considerado uma fonte de inovação; ii) a função know-how: está relacionada ao saber como fazer, ou seja, ao entendimento dos processos e dos procedimentos que criam combinações e vínculos entre os componentes, permitindo que o sistema funcione como um todo e; iii) a função know what que está diretamente relacionada à configuração que um produto deve ter para atender às necessidades do cliente (KUSUNOKI, 2008, p. 145) sendo considerada o núcleo central de onde ocorrem as inovações, podendo-se considerar assim que a "construção do conhecimento em uma organização é conseguida quando se reconhece o relacionamento sinérgico entre 0

\footnotetext{
${ }^{5}$ Ontológico: relativo à ontologia = teoria da ciência do ser enquanto ser considerado em si mesmo, independentemente do modo pelo qual se manifesta.

${ }^{6}$ Epistemológico: relativo à epistemologia = estudo do grau do conhecimento científico nos mais diversos ramos.
}

Perspectivas em Gestão \& Conhecimento, João Pessoa, v. 6, n. 2, p. 4-31, jul./dez. 2016 
conhecimento tácito e o conhecimento explícito" (CHOO, 2006, p. 37), valendo-se da interação entre eles para criar novos conhecimentos.

Conforme apresentado, em se tratando dos aspectos de geração de inovação a partir da utilização do conhecimento organizacional e seus métodos, observa-se duas questões importantes, a primeira é que o conhecimento pode ser considerado fruto do "know-how subjetivo, dos insights e intuições que uma pessoa tem depois de estar imersa numa atividade por um logo período de tempo" (CHOO, 2006, p. 37) e a segunda é que "a criação e aplicação do conhecimento em uma organização/empresa se dá pela sua capacidade de criá-lo, disseminá-lo e utilizá-lo em seus processos, produtos e serviços" (CORSATTO; HOFFMANN, 2011 , p. 138) de forma sistêmica e integrada na busca de soluções inovadoras, neste aspecto, a abordagem de Tidd et al. (2008, p. 35) converge com as visões apresentadas ao afirmar que "a inovação é uma questão do conhecimento que visa criar oportunidades por meio da combinação de diferentes conjuntos de conhecimentos." (TIDD et al., 2008, p. 35).

$E$, ainda, que o processo de construção do conhecimento organizacional está aportado nos indivíduos, se apresentando das mais diversas formas, seja como conhecimento tácito, técnico, empírico ou podendo já existir, ser fruto de uma experiência, ou ainda, podendo ser resultado de um processo de busca por tecnologias, mercados, ações da concorrência sendo, portanto, sua criação é possível na medida em que e os indivíduos se apropriam do conhecimento existente e estabelecem com este uma relação com seu próprio conhecimento tácito, construindo, neste movimento o conhecimento organizacional (VALENTIM, 2003; TIDD et al., 2008).

Entende-se que é nessas interações que ocorrem as conexões da aprendizagem, da criação do conhecimento e da geração da inovação na organização que aprende (learning organization), e, na inovação se dá a prática proposta pelo processo da open user innovation tratado a seguir e que oportunizam à organização/empresa a capacidade de criar novos corpos de conhecimentos e por consequência, expandir sua capacidade inovadora.

\subsection{A utilização de práticas de aprendizagem na organização que aprende (learning organization) e sua importância para a geração de inovação}

Tendo em vista a importância do aprendizado para a produção de conhecimentos, sua sistematização, sua utilização em diversos processos de gestão e de geração de produtos/serviços, vinculados à inovação, a partir da década de 1960 o tema da aprendizagem organizacional aparece nas discussões de alguns pensadores tal como Arrow (1962) que reconheceu que a evolução do conhecimento era uma constante, assumindo assim, a importância deste no processo de aprendizagem, tratando o aprendizado organizacional como um processo endógeno, porém construído com base nas externalidades.

Neste contexto Arrow (1962, p. 156) insere no processo de aprendizagem organizacional o modelo do "learning by doing" afirmando que o "aprender fazendo ocorre levando em conta o produto do investimento que as organizações/empresas fazem em seu processo produtivo." A abordagem de Arrow (1962) tem como foco principal as implicações econômicas do "aprender fazendo", na qual, segundo o autor,

[...] different subject to the same educational experiences have different bodies of knowledge, and we may therefore be prepared to grant, as has been shown empirically, that different countries, at the same moment of time, have different production functions even apart from differences in natural resource endowment. (ARROW,1962, p. 155).

Perspectivas em Gestão \& Conhecimento, João Pessoa, v. 6, n. 2, p. 4-31, jul./dez. 2016 
Como se pode observar, para Arrow (1962) indivíduos expostos à mesma experiência educacional podem desenvolver diferentes corpos de conhecimentos, isto ocorre em nível micro (na indústria, organização) e macro (no contexto e experiências de países) e pode determinar a curva de aprendizagem associada à atividade de produção uma vez que, conforme o autor o aumento de produtividade da economia poderia ser consequência da experiência na projeção de um produto ou realização de um processo.

Diante desta perspectiva Arrow (1962 p. 160) enfatizava que esta experiência dependia tanto do investimento como do estoque de conhecimentos ou do efeito educativo de cada investimento em aprendizagem, que por sua vez era proveniente do processo crescente do "aprender fazendo", que, conforme o autor reduz exponencialmente o tempo de fabricação de um produto, à medida que as habilidades vão aumentando. Seguindo a abordagem de aprendizagem organizacional com foco na prática do learning by doing Thompson (2010, p. 431) menciona que:

[...] a experiência de uma organização/empresa pode ser medida de várias formas, incluindo seu tempo de existência, os outputs gerados a partir das experiências acumuladas pela empresa, o tempo médio de permanência dos empregados e a duração média do trabalho relacionado à sua experiência.

Ainda conforme Thompson (2010, p. 43) learning by doing é "o nome coloquial atribuído pelos economistas ao fenômeno do crescimento da produtividade associado casualmente ao acúmulo de experiências em uma organização/empresa", principalmente após o período da evolução histórica das mudanças técnicas, da tecnologia, da inovação e do crescimento econômico ocorrido a partir destes eventos no final do século XIX e no século XX. Assim, partir da década de noventa, "ideia de uma organização que aprende ganhou crescente destaque." (SENGE, 1999, p. 4).

Com sua abordagem e visão sistêmicas o autor defendia que "[...] as melhores organizações do futuro serão aquelas que descobrirão como despertar o empenho e a capacidade de aprender das pessoas em todos os níveis da organização" (SENGE, 2008, p. 37). Considerando, conforme já visto, que a base central do conhecimento de uma organização está nas pessoas que a compõe, considerando a necessidade de estimular a capacidade de aprendizagem interna, do aprender fazendo, que coloca em evidência o "trabalhador do conhecimento" (DRUCKER, 1993, p. xvi) e que muda a concepção de mão-de-obra para a utilização dos conhecimentos, pode-se observar que as ideias de Senge (1999) ainda são atuais. Neste contexto, Senge (1999) enfatiza a importância das teorias, métodos e ferramentas que favorecem o desenvolvimento da aprendizagem organizacional ao afirmar que a utilização destas teorias, métodos e ferramentas lança nova luz sobre o significado do desenvolvimento das disciplinas para construir uma organização que aprende" (SENGE, 1999, p. 26), afirma ainda que "[...] o cerne do trabalho de organizações que aprendem baseia-se em cinco 'disciplinas de aprendizado' - programas perpétuos de estudos e práticas." (SENGE, 1999, p. 6). São elas:

Maestria Pessoal - aprender a expandir a nossa capacidade pessoal para criar resultados que mais desejamos, e criar um ambiente organizacional que estimule todos os seus membros a se desenvolverem na direção das metas e fins escolhidos;

Modelos Mentais - reflexionar, esclarecer continuamente e melhorar nossos quadros internos do mundo, e determinar como eles moldam nossas ações e decisões;

Perspectivas em Gestão \& Conhecimento, João Pessoa, v. 6, n. 2, p. 4-31, jul./dez. 2016 
Visão Compartilhada - construir um senso de compromisso em um grupo, desenvolvendo imagens compartilhadas do futuro que buscamos criar, e os princípios e práticas orientadoras pelos quais esperamos chegar lá;

Aprendizado em Equipe - transformar as habilidades conversacionais e coletivas de raciocínio, de modo que grupos de pessoas possam, confiavelmente, desenvolver inteligência e capacidade maiores do que a soma dos talentos dos membros individuais;

Pensamento Sistêmico - um modo de apreciar, e uma linguagem para descrever e entender, as forças e inter-relações que moldam o comportamento de sistemas. Esta disciplina ajuda-nos a entender como mudar sistemas de modo mais eficaz, e agir em melhor sintonia com os processos maiores do mundo natural e econômico. (SENGE, 1999, p. 6)

Para Senge (1999) as cinco disciplinas apresentadas trilham "um caminho de desenvolvimento sem fim" (SENGE, 1999, p. 6), levando a organização que aprende (learning organization) a um desempenho superior na busca da inovação e da vantagem competitiva.

Compostas por teorias, ferramentas, métodos, práticas, utilizando rotinas, receitas e procedimentos, as cinco disciplinas de Senge (1999), são consideradas práticas de aprendizagem onde a construção do conhecimento se dá a partir do aprendizado baseado nas experiências, valores e habilidades dos indivíduos, estando, portanto, em consonância com a proposta das organizações que estão em busca do aprendizado e que se preparam para fazer diferente e produzir inovações. E como, então, ocorre este processo de aprendizagem em uma empresa? Pode-se dizer que se trata de um processo que estimula a utilização prática dos conhecimentos, habilidades e experiências adquiridas pelas pessoas que estão "imersas numa atividade por um longo período de tempo", conforme afirmado por Choo (2006) e ainda, que essa prática está vinculada ao know-how conforme também já mencionado por Choo (2006) e por Kusunoku (2008) que dizem estar "a função know-how" relacionada ao saber fazer que estabelece conexões entre os processos e procedimentos que criam combinações entre conhecimentos tácitos, atividades e processos e que na sua concepção são agentes estimuladores de inovação.

Diante disso, pode-se inferir que o processo de aprendizagem e criação do conhecimento organizacional baseado nas características da learning organization estimula o exercício da visão sistêmica, contribui para a compreensão das interações da organização com seus ambientes interno e externo e apoia na compreensão de como alterar seus sistemas de modo mais eficaz, promover mudanças no modelo mental, estimulando desta forma a aprendizagem individual e conjunta e o avanço das organizações que aprendem para outras práticas de aprendizagem aportadas no sistema mercado.

Pode-se observar que as abordagens apresentadas referenciam prioritariamente o caráter endógeno e ontológico do processo de aprendizagem organizacional pela sua característica interna, no entanto, levando em conta a característica sistêmica trazida por Senge (1999) e considerando que o modelo sistêmico estimula as inovações desenvolvidas também por meio de cooperação com os agentes do mercado, pode-se ampliar esta característica de aprendizagem organizacional para o ambiente externo numa concepção de redes colaborativas que dão abertura à aprendizagem por meio do open user innovation.

\subsection{A utilização do Open user Innovation na geração de inovação}

Avançando para a abordagem da produção e utilização do conhecimento organizacional gerado nos processos de open user innovation e suas conexões com as formas de aprendizagem organizacional para a inovação, como se viu, tais processos têm início com a história e economia que ao longo do seu curso deram contribuições fundamentais para os

Perspectivas em Gestão \& Conhecimento, João Pessoa, v. 6, n. 2, p. 4-31, jul./dez. 2016 
estudos da evolução da tecnologia e inovação. Já naquele período havia tentativas de pesquisadores para o estudo sistemático da ocorrência de inovações por meio da co-criação ou cooperação, hoje denominada open innovation (inovação aberta). Neste processo entendese que o intercâmbio entre dois ou mais atores favorecem a apropriação de conhecimentos nas organizações estabelecendo relacionamentos, transpondo fronteiras, trocando conhecimentos entre uma diversidade de especialidades, facilitando o processo de inovação extramuros.

Assim, antes de abordar o tema e as características do modelo de atuação da open innovation, apresenta-se uma breve descrição do processo. O modelo da open innovation evoluiu com Henry Chesbroug, que em 2006 no seu livro Open Innovation: A new paradigm for understanding industrial innovation trouxe uma nova proposta de atuação no que se refere à inovação, que chamou de "inovação aberta". Este modelo, conforme Taurion (2007, p. 57), "desmonta o paradigma tradicional da cultura da pesquisa e desenvolvimento, uma vez que inverte as condições de pesquisa feita intramuros por uma única instituição ou empresa para um modelo de inovação aberta." Para o autor, "[...] este conceito trata a P\&D como um sistema aberto onde tanto ideias externas e internas são debatidas e as melhores alternativas são selecionadas" (TAURION, 2007, p. 57). Neste contexto, o modelo de Henry Chesbrough propõe:

[...] uma nova abordagem para a organização da pesquisa, desenvolvimento e inovação nas empresas, através da utilização de idéias externas em seu próprio processo de inovação, ao passo em que também disponibilizam para outras empresas idéias internas geradas em suas equipes de pesquisa e que não serão utilizadas em seu negócio. (Disponível em: http://pt.wikipedia.org/wiki/Henry Ches b $r$ ough. Acesso em: 14 nov. 2015).

Como se pode observar, a abordagem de Chesbrough (2006) propõe um modelo exógeno, sistêmico e integrado de produção do conhecimento que estimula as inovações desenvolvidas em conjunto com clientes e fornecedores, e considera as inovações surgidas a partir de outras inovações, mudando o paradigma da produção de conhecimento com base na pesquisa e desenvolvimento para uma concepção de cooperação ou co-criação ao que denominou de 'cooperação e desenvolvimento' sendo este, conforme Tidd et al. (2008, p. 73) "o movimento em direção à inovação aberta, em que vínculos e conexões se tornam tão importantes quanto a própria produção e propriedade do conhecimento." Esta abordagem evoluiu para o processo de inovação cooperativa, co-criada e com a participação de usuários finais nas organizações proposta por Von Hippel (2010). Conforme Von Hippel (2010, p.413), desde que Schumpeter (1934) apresentou a teoria do desenvolvimento econômico, economistas, políticos e gestores empresariais têm assumido que o modo dominante de inovação é em "modelo de produtos". Ou seja, assumiu-se que as inovações mais importantes se originaram dos produtos que são fornecidos aos consumidores por meio de bens que estavam à venda. No entanto, o modelo de inovação baseada em produtos, afirma Von Hippel (2010) é apenas um modelo de inovação. O autor apresenta um segundo modelo, que afirma ter ganhado importância no contexto econômico que é a "open user innovation" (VON HIPPEL, 2010, p. 413). Sobre este segundo modelo, conforme o autor, no que se refere à economia "[...] important innovations are developed by users and other agents who divide up the tasks and costs of innovation development and then freely reveal their results. Users obtain direct use benefits from the collaborative effort." (VON HIPPEL, 2010, p. 413). Além dos benefícios e dos esforços colaborativos, outros benefícios, tais como satisfação, aprendizado, reputação ou

Perspectivas em Gestão \& Conhecimento, João Pessoa, v. 6, n. 2, p. 4-31, jul./dez. 2016 
aumento da demanda para bens e serviços complementares, são ampliados a partir desta participação.

O que é então, open user innovation? Segundo Von Hippel (2010, p. 413), "open user innovation é o deslocamento da ocorrência da inovação para extramuros", ou seja, a inovação acontece a partir das necessidades dos usuários e é absorvida pelos produtores, o autor afirma que "um corpo crescente de trabalhos empíricos mostra claramente que os usuários são os primeiros a desenvolver a maioria e talvez os mais inovadores produtos industriais e bens de consumo", (VON HIPPEL, 2010, p. 413) e ainda tem a função de aumentar o bem-estar social.

Diante disso, Von Hippel (2010) fez uma revisão dessa aprendizagem coletiva para desenvolver sua abordagem da inovação colaborativa com a participação dos consumidores, dividindo-a em tópicos que são apresentados a seguir. Para Von Hippel (2010) uma questão fundamental nesta aprendizagem é a importância da inovação "by user", onde usuários ou user, conforme esclarece o autor, são "firms or individual consumers that expect to benefit from using a product or a service." (VON HIPPEL, 2010, p. 413).

O segundo tópico importante, de acordo com o autor, verifica por que muitos usuários querem produtos customizados. Na visão do autor, usuários também inovam suas percepções e com isso passam a desejar algo que não está disponível no mercado estando dispostos a pagar pelo seu desenvolvimento; desta forma o terceiro tópico aborda a decisão do usuário: inovar ou comprar? No processo de user innovation, explica Von Hippel (2010, p. 414), esta decisão é exclusiva do usuário, que embora possa comprar o que deseja, escolhe produzir a própria inovação ao invés de contratar um produtor para desenvolver um produto customizado. Em seguida, o autor traz os nichos de inovação de baixo custo que se referem diretamente à geração, disponibilidade e uso da informação necessária para exploração básica dos processos de desenvolvimento de produtos e serviços, uma vez que, conforme mostra Von Hippel (2010, p. 418), usuários e produtores têm conhecimentos diferentes devido à assimetria de informações, por isso tendem a desenvolver diferentes tipos de inovação.

A quinta questão abordada reflete o por que os usuários muitas vezes revelam suas inovações livremente? Neste item o autor afirma que, ao dizer que um inovador revela livremente informações sobre os produtos e serviços que desenvolve, quer dizer com isso que abriu mão dos direitos de propriedade intelectual sobre eles de forma que qualquer parte interessada pode ter acesso às informações, uma vez que elas se tornam um bem público.

$\mathrm{O}$ autor incluiu ainda, na lista de tópicos relevantes para a aprendizagem coletiva, a importância das comunidades de inovação que têm a finalidade de concentrar as inovações, uma vez que pela sua característica de open user innovation tende a ficar distribuída entre alguns poucos grupos dispersos (VON HIPPEL, 2010, p. 421); a necessidade de adaptação das políticas para user innovation uma vez que, com relação à existência ou não de políticas públicas ou a adaptação delas para este tipo de inovação em uma economia onde predomina a cultura de que só aos produtores é permitido inovar, uma constatação é premente, a de que as políticas, legislação e regulamentos devem ou deveriam apoiar os user innovatiors ou pelo menos garantir que as políticas em geral não favorecessem apenas os produtores (VON HIPPEL, 2010, p. 422). O autor finaliza a revisão dessa aprendizagem coletiva abordando as questões referentes à difusão de inovações desenvolvidas pelo usuário, já que se as inovações do usuário não forem difundidas, diz Von Hippel (2010, p. 423), outros usuários com necessidades parecidas terão que investir para desenvolver inovações semelhantes.

Em resumo, a visão dessa aprendizagem coletiva que ocorre por meio das práticas desenvolvidas pela open user innovation, que tem como fonte de inovação a ideia e o desejo do usuário e se dá na capacidade de inovar, que tem um papel de consumidor pró-ativo, onde

Perspectivas em Gestão \& Conhecimento, João Pessoa, v. 6, n. 2, p. 4-31, jul./dez. 2016 
a empresa desenvolve seus produtos "capitalizando no potencial criativo dos usuários ${ }^{7 "}$ e onde a inovação acontece em parte de forma radical e muito rápida tendo impactos profundos na capacidade de aprendizado, no aprender fazendo e no processo de geração de inovação.

\section{CONSIDERAÇÕES FINAIS}

Como se pode observar, em que pese o processo de evolução histórica das mudanças técnicas, tecnológicas e da inovação ter suas evidências registradas a partir do século XVIII até os tempos atuais, a ideia da observação da ocorrência desta evolução a partir da produção do conhecimento e aprendizagem nas organizações é recente, particularmente no que se refere ao conhecimento e competências aportado nas pessoas e sua utilização individual e coletiva para a geração da inovação. Neste contexto, este artigo se pautou na proposta de apresentar os impactos da produção do conhecimento organizacional na geração da inovação, revisandoos à luz das contribuições históricas e econômicas dos estudos da inovação e sua evolução a partir das mudanças técnicas, avanços tecnológicos e suas interações endógenas e exógenas com a produção do conhecimento organizacional, sua importância no processo de inovação, bem como as conexões estabelecidas com as formas de aprendizagem organizacional, tratando especificamente dos processos de aprendizagem nas learning organization e da prática do open user innovation.

Diante desta proposta, pode-se considerar que o propósito de apontar tais contribuições, interações e conexões, trazendo o histórico das mudanças técnicas, a evolução das tecnologias e as conseguintes inovações desenvolvidas a partir do conhecimento e do processo de aprendizagem de uma organização e da utilização das práticas definidas para esta discussão, foi atendido. Entende-se que foi atendida também a proposta de conceituar tecnologia e inovação e avançar na abordagem da produção de conhecimentos para a geração de inovações contextualizando seus impactos na produção de conhecimentos da mesma natureza, sob o ponto de vista da utilização de práticas de aprendizagem em open user innovation pelas learning organizations.

Desta forma, considerando que os processos e práticas apresentadas trazem à pauta a discussão das diversas nuances do conhecimento nas organizações que transitam nas prerrogativas da produção e utilização do conhecimento interno versus o externo existente no ambiente onde estão inseridas essas organizações, e ainda, considerando que Nonaka e Takeuchi (2008) dão ao contexto da produção do conhecimento uma visão sistêmica ao afirmarem que "[...] uma organização cria novos conhecimentos convertendo o conhecimento tácito em conhecimento explícito e vice-versa" (NONAKA; TAKEUCHI, 2008, p. 19) pode-se entender que a produção do conhecimento em uma organização perpassa pelas esferas do conhecimento tácito e do explícito. Pode-se entender ainda que estes são elementos de fundamental importância na produção do chamado conhecimento organizacional, uma vez que, conforme Senge (1999) em uma organização que aprende a produção do conhecimento envolve toda a organização e implica na adoção de novas formas de aprendizado, baseadas na filosofia da Learning Organization, onde as pessoas aprendem a trabalhar em equipe e, a partir dessa interação e da soma das competências individuais, garante a apropriação do conhecimento coletivo e o fortalecimento da cultura organizacional.

$\mathrm{E}$, ainda, considerando a prerrogativa de que o processo de inovação em uma organização/empresa ocorre a partir das conexões do processo de aprendizagem e da criação de um corpo de conhecimentos adequados em suas combinações técnicas, operacionais, estratégicas, tácitas, empíricas etc. e considerando a utilização das práticas apresentadas para

\footnotetext{
7 Disponível em: http://www.innovationmanagement.se/2014/07/15/como-as-empresas-exploram-opotencial-de-usuarios-inovadores-quatro-exemplos-da-alemanha/. Acesso em: 20 dez. 2015.
}

Perspectivas em Gestão \& Conhecimento, João Pessoa, v. 6, n. 2, p. 4-31, jul./dez. 2016 
a produção do conhecimento e aprendizagem organizacional, entende-se ser recomendável que a combinação dos tipos de conhecimentos envolvidos nos diferentes tipos de inovação seja cuidadosa. Recomenda-se também que a empresa/organização esteja ciente da existência ou disponibilidade interna dos conhecimentos necessários para desenvolver projetos inovadores ou reconheça a necessidade de buscá-lo em fontes externas uma vez que, conforme Choo (2006, p. 224) "a construção do conhecimento não é mais uma atividade em que a organização trabalha isolada, mas o resultado da colaboração entre seus membros, seja em grupos internos, seja em parceria com outras organizações" (CHOO, 2006, p. 224), já que, conforme constatado por meio de processo de observação real e prática das pesquisadoras, não raro, se encontra organizações que não reconhecem a interação existente entre se atribuir importância ao conhecimento e à busca pela aprendizagem organizacional e por consequência restringem ou na pior das hipóteses não desenvolvem estratégias de aproveitamento do conhecimento útil e da aprendizagem gerados na organização para a geração de inovação.

\section{REFERÊNCIAS}

ARROW, Kenneth J. The Economic Implication of Learning by Doing. Review of Economics Studies, Oxford, v.29, n.3, p.155-173, jun.,1962. Disponível em: http:// www.jstor.org/sta ble/2295952. Acesso em: $18 \mathrm{dez} .2015$.

CHESBROUGH, Henry. Open Innovation Seminar-Brazil: Open Innovation a new approach to Industrual R\&D. São Paulo: Pioneira, 2009.

Henry. Open innovation: a new paradigm for understanding industrial innovation. In: Financiamento à Inovação: Curso avançado para captação em PI. Cuiabá: FINEP/MCT, março de 2009.

CHOO, Chun Wei. A organização do conhecimento: Como as organizações usam a informação para criar significado, construir conhecimento e tomar decisões. 6. ed. São Paulo: Ed. SENAC, 2006.

CORSATTO, Cássia Ap. A importância do conhecimento organizacional para a inovação: uma abordagem das mudanças técnicas, tecnológicas e a evolução da inovação para o conhecimento organizacional. In: HOFFMANN, Wanda Ap .M. (Org.). Construções interdisciplinares em gestão do conhecimento. São Carlos: Pedro\&João Editores, 2016. p.1131.

CORSATTO, Cássia A.; HOFFMANN, Wanda A. M. Gestão de desafios: conhecimento, inovação e sustentabilidade. In: HOFFMANN, Wanda Ap.M.(Org.). Ciência, tecnologia e sociedade: desafios da construção do conhecimento. São Carlos: EdUFSCar, 2011. p. 137-153.

A produção do conhecimento científico, tecnológico e organizacional no contexto da geração de inovação e sua relação com a ciência da informação. In: ENCONTRO NACIONAL DE PESQUISA EM PÓS-GRADUAÇÃO EM CIÊNCIA DA INFORMAÇÃO, 16., 2015, João Pessoa. Anais... João Pessoa: ANCIB, 2015. Disponível em: http://basessibi.c3sl. ufpr.br/brapci/index.php/article/view/0 000017 532/70807 e2795cace9f090c82150268f455. Acesso em: 14 dez. 2015.

DAVENPORT, Thomas H.; Prusak, Laurence. Conhecimento Empresarial: Como as organizações gerenciam seu capital intelectual: Métodos e aplicações práticas. 14. ed. Tradução de Lenke Peres. Rio de Janeiro: Elsevier, 2003.

DAVILA, Tony; EPSTEIN, Marc J.; SHELTON, Robert. As regras da inovação. Tradução de Raul Rubenich. Porto Alegre: Bookman, 2007.

Perspectivas em Gestão \& Conhecimento, João Pessoa, v. 6, n. 2, p. 4-31, jul./dez. 2016 
DOSI, Giovanni; NELSON, Richard R. Technical change and industrial dynamics as evolutionary processes. In: HALL, Bronwyn H.; ROSENBERG, Nathan (Org.). Handbook of the economics of innovation. Amsterdam: Elsevier, 2010. v.1. cap.3

DRUCKER, Peter F. Sociedade pós-capitalista. 2. ed. Tradução de Nivaldo Montingelli Jr. São Paulo: Pioneira, 1993.

FELDMAN, Maryann P.; KOGLER, Dieter F. Stylized facts in the geography of innovation. In: HALL, Bronwyn H.; ROSENBERG, Nathan (Org.). Handbook of the economics of innovation. Amsterdam: Elsevier, 2010. v.1. cap. 8.

FIGUEIREDO, Paulo N. Gestão da Inovação: Conceitos, métricas e experiências de empresas no Brasil. Rio de Janeiro: LTC, 2015.

FORAY, Dominique; LUNDVALL, Bengt-Ãke. From economics of knowledge to the learning economy.Employement and growth in the knowledge-based economy. Paris: OCED, 1996.

FREEMAN, Christopher. Innovation and the strategy of the firm. In: The economics of industrial innovation. Harmondsworth: Penguin Books, 1974. p. 224-88.

GALOR, Oded. Convergence? inferences from theoretical models. The Economic Journal, Oxford, v. 106, n. 437, p. 1056-1069, July, 1996. Dsiponivel em: https://www.jstor.org/ stable/2235378?seq=1\#page scan tab contents. Acesso em: 11 mar.2015.

KUHN, Thomas S. A estrutura das revoluções cientificas. 11. ed. Tradução de Beatriz Vianna Boeira e Nelson Boeira, São Paulo: Perspectiva, 2011

KUSUNOKI, Ken. Diferenciação de valor: Organização do know-what para a inovação do conceito de produto, cap.6. In: NONAKA, Ikujiro; TAKEUCHI, Hirotaka. Gestão do Conhecimento. Tradução de Ana Thorell. Porto Alegre: Bookman, 2008.

MANSFIELD, E. Industrial research and technological innovation: an econometric analysis. New York: W.W. Norton, 1968.

MOKYR, J. The contribuition of economics history to the study of innovation and technical change: 1759 - 1914. In: HALL, Bronwyn H.; ROSENBERG, Nathan (Org.). Handbook of the economics of innovation. Amsterdam: Elsevier, 2010. v.1. cap. 2

MORESI, Eduardo A. Dutra. O contexto organizacional. In: TARAPANOFF, Kira (Org.). Inteligência organizacional e competitiva. Brasília: Editora Universidade de Brasília, 2001.

NELSON, Richard R.; WINTER, Sidney G. An evolutionary theory of economic change. Cambridge: Harvard University Press, 1982.

NOGUEIRA, Ronaldo A.; ODELIUS, Catarina C. Aprendizagem: evolução no contexto das teorias das organizações. Revista Perspectiva em Gestão\&Conhecimento, João Pessoa, v.5, n.1, p.318, jan./jun., 2015 Disponível em: http://periodicos.ufpb.br/ojs/index.php/pgc/articl e/view/17286/13418. Acesso em: 08 jul. 2016.

NONAKA, Ikujiro; TAKEUCHI, Hirotaka. Gestão do Conhecimento. Tradução de Ana Thorell. Porto Alegre: Bookman, 2008.

ORGANIZAÇÃO PARA COOPERAÇÃO E DESENVOLVIMENTO ECONÔMICO. Manual de Oslo: diretrizes para a coleta de dados sobre inovação. 3. ed. Brasília: FINEP, 2005.

ROCHA, Ivan. Ciência, tecnologia e inovação: conceitos básicos. Brasília: Sebrae, 1996.

SÃENZ, Tirso W; CAPOTE, Emilio G. Ciência, Inovação e Gestão tecnológica. Brasília: CNI/IEL/SENAI, 2002.

Perspectivas em Gestão \& Conhecimento, João Pessoa, v. 6, n. 2, p. 4-31, jul./dez. 2016 
SCHUMPETER, J. A. Teoria do desenvolvimento econômico: uma investigação sobre lucros, capital, crédito, juro e o ciclo econômico. Tradução de Maria Silvia Possas. São Paulo: Editora Nova Cultural, 1985. (Série Os economistas).

Capitalismo, Socialismo e Democracia. Tradução de Ruy Jungmann. Rio de Janeiro: Editora Fundo de Cultura, 1961. (Série Os economistas).

SENGE, Peter M. A quinta disciplina: arte e prática da organização que aprende. Tradução de OP Traduções. Rio de Janeiro: BestSeller, 2008.

A quinta disciplina: caderno de campo - estratégias e ferramentas para construir uma organização que aprende. Tradução de Antonio Roberto Maia da Silva. Rio de Janeiro: Qualymark Ed., 1999.

SNOW, C. P. As duas culturas e uma segunda leitura: uma versão ampliada das duas culturas e a revolução científica. São Paulo: EDUSP, 1963.

STEWART, Thomas A. Capital intelectual: a nova vantagem competitiva das empresas. Tradução de Ana Beatriz Rodrigues. Priscilla Martins Celeste. Rio de Janeiro: Campus, 1998.

TAVARES, Paulino V.; KRETZER, Jucélio; MEDEIROS, Natalino. Economia Neoschumpeteriana: expoentes evolucionários e desafios endógenos da economia brasileira. Economia - Ensaios, Uberlândia, v. 20, n. 1, p. 105-120, dez. 2005. Disponível em: http://www.seer.ufu.br/index.Índex.php/revistaeconomiaensaios/article/view/1551. Acesso em: 11 mar. 2015.

TEECE, David J. Technological innovation and the theory of firm: The role of enterprise-level knowledge, complementarities and (dynamic) capabilities. In: HALL, Bronwyn H.; ROSENBERG, Nathan (Org.). Handbook of the economics of innovation. Amsterdam: Elsevier, 2010. v.1. cap.16.

THOMPSON, Peter. Learning by doing. In: HALL, Bronwyn H.; ROSENBERG, Nathan (Org.). Handbook of the economics of innovation. Amsterdam: Elsevier, 2010. v.1. cap. 10

TIDD, Joe; BESSANT, John; PAVITT, Ketih. Gestão da Inovação. 3. ed. Tradução de Elizamari Rodrigues Becker et al. Porto Alegre: Bookmann, 2008.

VALENTIM, Marta L. P. A construção do conhecimento em organizações. InfoHome Ofaj. Marília, p.1, set. 2003. Disponível em: http://www.ofaj.com.br/colunas conteudo.Php?Cod =76. Acesso em: 07 jul. 2016.

VIOTTI, Eduardo Baumgratz et al. Dimensão econômica da inovação. Brasília: ABIPTI/Sebrae, 1997.

VON HIPPEL, Eric. Open user innovation. In: HALL, Bronwyn H.; ROSENBERG, Nathan (Org.). Handbook of the economics of innovation. Amsterdam: Elsevier, 2010. v.1. cap. 9. 